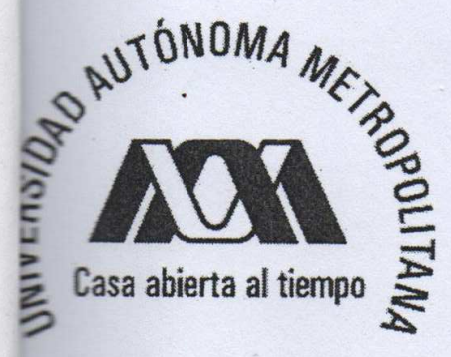

IVERSIDAD AUTONOMA METROPOLITANA-UNIDAD IZTAPALAPA VISION DE CIENCIAS BASICAS E INGENIERIA

\title{
CARACTERIZACIÓN DE LA PERFUSIÓN POR RESONANCIA MAGNÉTICA EN UN MODELO DE TRATAMIENTO DE INFARTO CEREBRAL. \\ que presenta:
}

\section{ANDREA GARCÍA QUINTANAR}

Para obtener el grado de:

Maestría en Ciencias en Ingeniería Biomédica

Aprobada por:

Dr. Emilio Sacribtán Rock
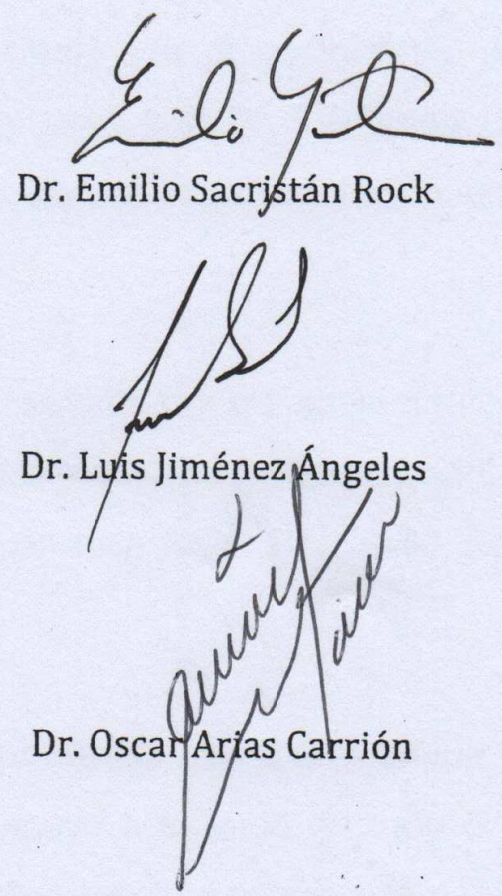

Octubre del 2013. México D.F. 


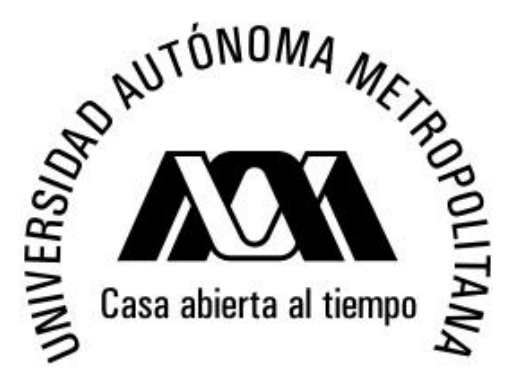

UNIVERSIDAD AUTONOMA METROPOLITANA-UNIDAD IZTAPALAPA DIVISION DE CIENCIAS BASICAS E INGENIERIA

\title{
CARACTERIZACIÓN DE LA PERFUSIÓN POR RESONANCIA MAGNÉTICA EN UN MODELO DE TRATAMIENTO DE INFARTO CEREBRAL.
}

\author{
que presenta: \\ ANDREA GARCÍA QUINTANAR \\ Para obtener el grado de: \\ Maestría en Ciencias en Ingeniería Biomédica
}

Aprobada por:

Dr. Emilio Sacristán Rock

Dr. Luis Jiménez Ángeles

Dr. Oscar Arias Carrión

Octubre del 2013. México D.F. 



\section{AGRADECIMIENTOS}

Agradezco a todas las personas que contribuyeron en la planeación, desarrollo y la realización de esta investigación.

Gracias al equipo del Centro Nacional de Investigación en Imagenológia e Instrumentación Médica (CI3M) por su constante apoyo y asesoría en la elaboración del protocolo de investigación, asi como en la realización de los experimentos: PARI. Iván Mejía, Ing. Andres Moron, Ing. Adrian Gonzalez, Ing. Fernanda Maldonado y Rafael Lara. Y la ayuda administrativa de Elizabeth Ramírez.

Gracias a todos los colaboradores para este proyecto: MVZ. Juan Ramón Torres Ríos, Dr. Gerardo Villanueva Manzano y al Dr. Fernando Castro por su gran ayuda en la elaboración del protocolo y la experimentación, así como su apoyo y asesorías ofrecidas.

Gracias a todos mis asesores y maestros por transmitirme su conocimiento y su apoyo incondicional a lo largo de la planeación, organización, experimentación y procesamiento de los resultados de esta tesis: Dr. Emilio Sacristan Rock y Dr. Joaquin Azpiroz Leehan

Gracias al Dr. Mark K. Borsody por la confianza depositada para la realización de este protocolo, así como su apoyo a lo largo de todo el proceso, y por su constante determinación que es un ejemplo a seguir. 
Ing. Andrea García Quintanar

UAM-Iztapalapa

Este trabajo se realizo con el apoyo financiero de Lake Bio Science.

Agradezco a CoNACyT por la beca otorgada como apoyo para mis estudios de maestría, así como a la fundación UAM-ICYTDF por el estimulo económico recibido en apoyo a asistencia a congresos.

Finalmente gracias al $\mathrm{Cl} 3 \mathrm{M}$ por el apoyo de toda forma recibido a lo largo de mi maestría y sin el cual esto no podría existir. 


\section{DEDICATORIAS}

Agradezco el apoyo de mis padres, por su comprensión, buen ejemplo y siempre el demostrarme que el limite es el cielo. Gracias a los dos por estar presente en todo momento.

Agradezco a mis hermanas, Adriana y Gabriela, que han sido parte importante de mi formación y que no puedo negar que han sido un motor valioso en mi vida, no importa donde estemos siempre nos tendremos la una a la otra.

Agradezco a mi Familia en general, a mis tíos, Gerardo y Catalina, Fernando Ponce y a mis primos Luisa y Gerardo por sus grandes consejos, por las discusiones acerca del universo, por las grandes confabulaciones mafiosas.

Gracias a todos mis amigos que siempre han demostrado estar conmigo, en las buenas y en las malas. Gracias por creer en mi y apoyarme cuando incluso creo estar mal.

Finalmente agradezco a mis profesores a lo largo de mi vida académica ya que me han demostrado que esta vida de investigador es una vida hermosa llena de altibajos pero destinada siempre al descubrimiento de conocimiento. Gracias Emilio, Joaquín, Fabiola y Miguel por escucharme y por ayudarme en todo momento, los considero parte de mi familia. 


\section{RESUMEN}

El infarto cerebral afecta alrededor de 15 millones de pacientes al año y es una de las causas principales de muerte a nivel mundial. Los tratamientos disponibles son solo indicados para menos del $5 \%$ de la población de los pacientes. Los factores de riegos para el infarto cerebral son: hipertensión, cardiopatías, tabaquismo, dislipidemias, sedentarismo, diabetes mellitus y nefropatías. Estos mismos factores están contraindicados en los tratamientos disponibles.

La estimulación del nervio facial ha sido propuesto como un posible nuevo tratamiento para enfermedad cerebro vascular (EVC) isquemico. Dicha estimulación actúa incrementando el flujo sanguíneo del cerebro para poder restaurar la perfusión a través de la circulación colateral.

El objetivo de esta tesis fue el evaluar los cambios de la perfusión en cerebro debidas a la estimulación del nervio facial en un modelo canino usando mediciones de flujo sanguíneo cerebral por medio de IRM.

El protocolo para evaluar la técnica de restauración de la perfusión en un modelo de infarto cerebral incluye la generación del mismo. El infarto cerebral fue generado con la oclusión de la arteria media cerebral (AMC) a través de la inyección de coágulos autólogos en la carótida interna en 17 perros de raza mixta. La oclusión fue verificada por medio de fluoroscopia y angiografía por resonancia magnética (RM). Y monitorizada por la toma de imágenes por RM en los siguientes tiempos: línea de base (LB), post-infarto (PI), post-estimulacion (PEstim o $T=0$ ) y cada 30 minutos posteriores $(T=30, T=60, T=90)$ hasta 60 o 90 minutos. Se realizo la localización del tronco del nervio facial y el ganglio geniculado, y este último fue estimulado después de la confirmación del infarto, usando una estimulación magnética transcraneal (TMS) y un sistema de 
neuronavegación en 11 de los animales (grupo de estimulación). Seis animales siguieron el mismo procedimiento pero no fueron estimulados (grupo control).

El índice de perfusión fue medido en ambos lados del cerebro usando medio de contraste para RM antes y después del infarto, y cada 30 minutos después de la estimulación.

Los resultados muestran un incremento significativo y persistente en perfusión del lado infartado relativo al lado no infartado, cuando comparamos entre grupos. Estos resultados demuestran que este tipo de tratamiento es eficaz y apoyan el desarrollo futuro de un estimulador del nervio facial no invasivo como tratamiento temprano para infartos isquémicos.

Así también los resultados arrojados de la medición del flujo en las carótidas externas muestran que existe un incremento del flujo del lado estimulado. El grupo de estimulación con respecto al grupo control muestra que este incremento es persistente al menos por 30 minutos posteriores a la estimulación.

La espectroscopia fue realizada en tres ocasiones: en línea de base, post estimulación y sesenta minutos después de esta. En ambos grupos se muestra que la relación ATP/P total (indicador metabólico), cae después del infarto; sin embargo, en el grupo de estimulación la relación aumenta con respecto al tiempo, contrario al grupo control, donde se muestra un decaimiento y al tiempo sesenta minutos la relación esta por debajo del 0.60 .

Los resultados indican que la aplicación de TMS en nervio facial, focalizada en el ganglio geniculado, provoca un incremento en la perfusión de acuerdo al modelo utilizado, además de que dicho efecto es corroborado por otras mediciones imagenológicas; como lo son la velocidad del flujo y la medición metabólica. Esto indica que el tejido responde al tratamiento presentando un aumento metabólico 
Ing. Andrea García Quintanar

UAM-Iztapalapa

del tejido de muy baja perfusión y baja perfusión, insinuando que puede existir una elongación de la ventana terapéutica. 


\section{INDICE}

\section{INTRODUCCIÓN}

1.1 ENFERMEDADES CEREBRO-VASCULARES

1.2 TRATAMIENTOS PARA EVC

1.3 ESTIMULACIÓN MAGNÉTICA TRANSCRANEAL

1.4 NERVIO FACIAL

1.5 RESONANCIA MAGNÉTICA NUCLEAR

1.6 ESPECTROSCOPÍA POR RESONANCIA MAGNETICA (ERM)

1.7 NEURONAVEGACIÓN

1.8 PROTOCOLO PILOTO DE EVC CON TMS EN OVEJAS

1.8.1 RECURSOS MATERIALES

1.8.2 MODELO EN OVEJAS

2. HIPÓTESIS

3. OBJETIVOS

4. METOdologíA

4.1 TRATAMIENTO DE LOS ANIMALES, MODELO CANINO

4.2 INDUCCIÓN DE EVC ISQUEMICO

4.3 NEURONAVEGACIÓN EN EL MODELO

4.4 PROTOCOLO IMAGENOLÓGICO

5. RESULTADOS

5.1 RESULTADOS DE PERFUSIÓN

5.2 RESULTADOS DE MEDICIÓN DEL FLUJO

5.3 RESULTADOS DE ${ }^{31 P}$

6. DISCUSIÓN 
Ing. Andrea García Quintanar

UAM-Iztapalapa

7. CONCLUSIÓN

8. RECOMENDACIONES DE TRABAJO A FUTURO

9. LISTA DE FIGURAS Y TABLAS

10. BIBLIOGRAFÍA

11. ANEXOS

Anexo I. Pruebas neurológicas utilizadas en la clínica

Anexo II. Protocolo en tiempos utilizado.

81 


\section{INTRODUCCIÓN}

\subsection{ENFERMEDADES CEREBRO-VASCULARES}

El cerebro constituye uno de los órganos que a lo largo de la historia ha sido objeto de estudio debido a la complejidad de sus estructuras y su comunicación. Uno de los primeros estudiosos de la materia fue Hipócrates que hace aproximadamente 2400 años hizo la primera visualización y descripción de una de las enfermedades que hoy en día representan una de las principales causas de morbilidad y mortalidad alrededor del mundo, así como la cuarta causa de muerte en los Estados Unidos: el infarto cerebral, también llamado Enfermedad Vascular Cerebral (EVC)[1].

Las muertes asociadas al EVC se dan una cada cuatro minutos a nivel mundial, existiendo una prevalencia de razas de $0.88 / 1000$ blancos, $1.91 / 1000$ negros y 1.49/1000 hispánicos, siendo el sexo masculino el que tiene mayor incidencia[1].

Existen dos tipos de enfermedades: EVC isquémico y EVC hemorrágico, el hemorrágico se subdivide en intraparenquimatoso y extraparenquimatiso. Representando una prevalencia de $87 \%, 13 \%$ respectivamente[2]. 
Ing. Andrea García Quintanar

UAM-Iztapalapa

Los principales factores de riesgo del EVC son[3]:

- Hipertensión

- Cardiopatías

- Tabaquismo,

- Colesterol y otros lípidos altos,

- Sedentarismo,

- Diabetes mellitus y

- Nefropatías.

Los síntomas han sido utilizados como referencia de detección de tipo de EVC que se presenta, sin embargo el paciente debe de acudir al centro medico mas cercano al presentar:

- Debilidad o adormecimiento en un brazo, una pierna o la mitad de la cara.

- Confusión o Dificultad para hablar o entender.

- Problemas para ver con uno o ambos ojos.

- Perdida del equilibrio o de coordinación.

- Dolor de cabeza muy intenso

En cualquier tipo de EVC las guías medicas refieren la necesidad de decisión del tratamiento en los primero 60 minutos; bajo la aplicación de las siguientes pruebas se puede determinar el tipo de evento y el tipo de tratamiento a aplicar (ver anexo 1):

- Evaluación neurológica completa y exploración clínica integral usando la escala NIHSS.

- Empleo de escalas de valoración estándares como FAST(Face Arm Speech Test) o MASS.

- Valoración del estado neurológico mediante la escala de Glasgow.

El EVC isquémico es producido por una obstrucción en alguna arteria del cerebro (ver figura 1). El cerebro depende de la red cerebrovascular para el transporte de oxigeno, nutrientes y para el desecho de bióxido de carbono junto 
con otros productos de eliminación celular. Cuando una arteria se encuentra obstruida el proceso de transporte activo y pasivo se ve suspendido y eventualmente las células mueren.

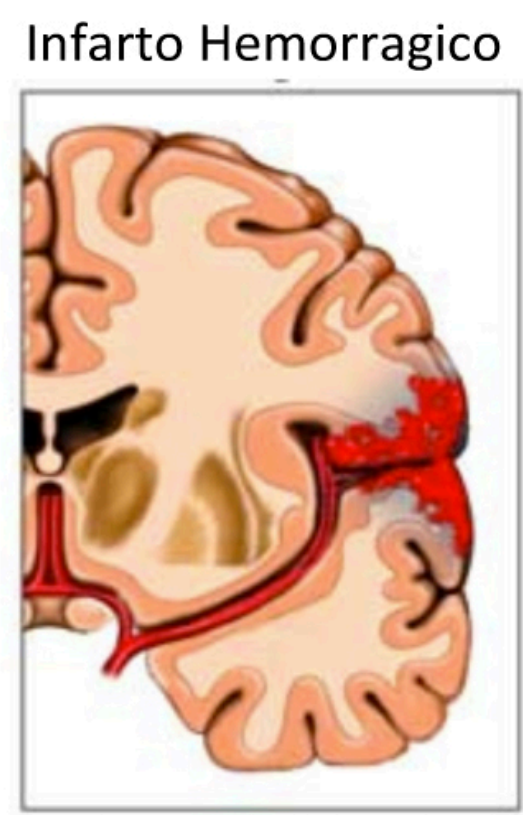

La hemorragia se riega dentro del tejido cerebral
Infarto Isquemico

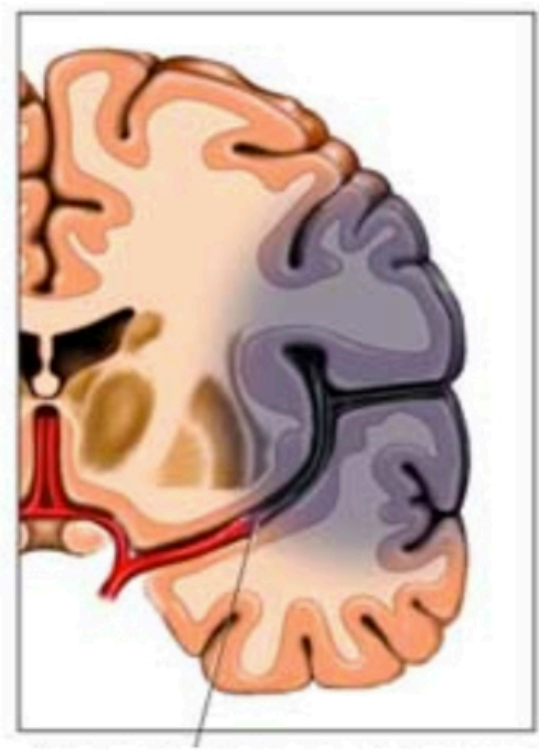

El coagulo detiene el flujo al tejido cerebral

Imagen tomada de $\mathbb{R}$ Nucleus Medical Media Inc.

Figura1. Infarto isquémico y hemorrágico

En el EVC isquémico, como se muestra en la figura 1 del lado derecho, el riego sanguíneo empieza a ser insuficiente, por lo tanto los tejidos cambian su metabolismo. Se puede clasificar en tres tipos: umbra, penumbra y tejido sano[15]. El tejido de umbra es aquel que se considera tejido necrosado. El tejido de penumbra se considera reversible o salvable, ya que en caso de lograr la restauración de flujo dentro de la ventana terapéutica, este tejido se oxigena, logrando regresar a homeostasis. Una forma de reconocer los tipos de tejido es 
Ing. Andrea García Quintanar

UAM-Iztapalapa

por medio de potenciales evocados los cuales resultan ser anormales en comparación con tejido sano.

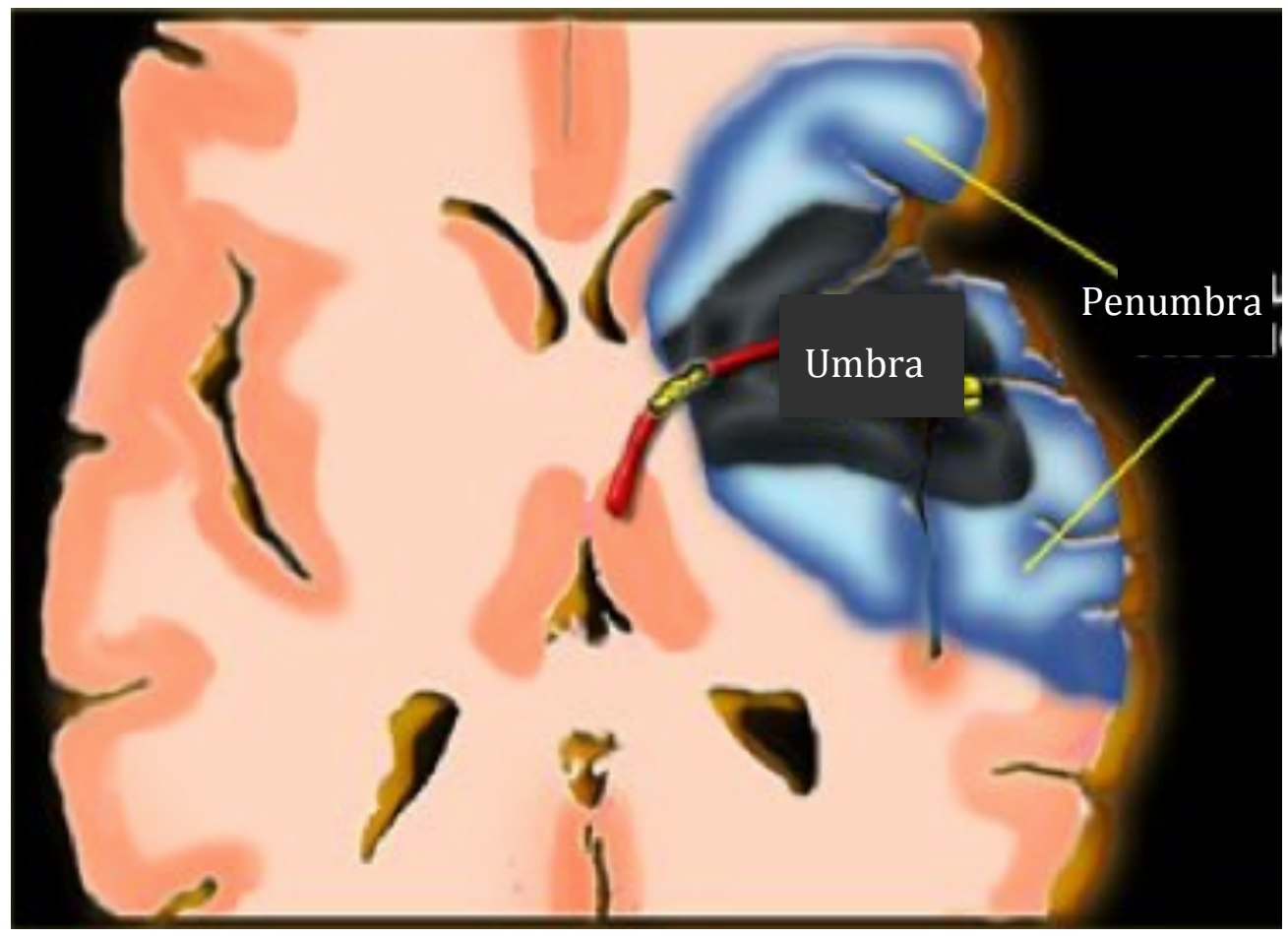

Figura 2. Figura que muestra la clasificación por tipo de tejido; umbral y penumbra

Figura que muestra el esquema de la clasificación del tejido después de un EVC isquémico. El área de umbra aquella donde el tejido se considera muerto. El área de penumbra es considerada tejido reversible.

(Thurner, 2008)

Los tratamientos de emergencia para el EVC isquémico se centran en la restauración del Flujo Sanguíneo Cerebral (FSC), alrededor de la oclusión. Estos pueden ser de dos tipos: los que tienen como objetivo la disolución de los coágulos mediante fármacos 0 la remoción mediante intervenciones endovasculares / intravasculares [6].

Dentro de las guías clínicas para el tratamiento[1,2,3] de EVC se realiza un diagnóstico temprano del tipo de EVC, esto requiere usualmente el uso de técnicas imagenológicas como la Tomografía Axial Computarizada (TAC), Imagenología por Resonancia Magnética (IRM), entre otras. La evaluación y el 
diagnóstico del paciente es prioritario, debido a que es una enfermedad que se vuelve más compleja y causa más estragos con el paso del tiempo[5].

Existe una llamada ventana terapeutica[15] después del EVC, de la cual depende el pronóstico para la recuperación neurológica; en donde entre más tiempo transcurra, la recuperación se vuelve mas pobre[2]. Es necesario actuar en un lapso de tres a cuatro punto cinco horas para tener alta probabilidad de recuperación[1], pero el tiempo antes de iniciar las intervenciones toma al menos una hora, de tal manera que si se pudiera extender la ventana de tiempo, el impacto en el pronóstico para la rehabilitación del paciente se incrementaría notablemente.

Dado que el tiempo es una variable vital en el proceso de tratamiento, se han creado protocolos para el tratamiento y la evaluación del paciente[1]. Uno de los principales protocolos es el perteneciente a la American Stroke Association. El procedimiento es el siguiente: Al llegar el paciente al hospital se deberá tratar de estabilizar signos vitales y enseguida una evaluación neurológica y de comorbilidad. En esta evaluación se busca una adecuada clasificación del paciente así como la búsqueda de la causa que pudo haber detonado el EVC. Posterior a esta evaluación se realiza la técnica imagenológica más conveniente y disponible para la determinación del tipo de EVC, y de acuerdo con el historial del paciente, el tiempo y el diagnóstico imagenológico se somete al paciente (en caso de calificar) al tratamiento adecuado[1,2].

\subsection{TRATAMIENTOS PARA EVC}

Actualmente se emplean en general dos terapias para el tratamiento agudo de los EVC. Cabe mencionar que el costo de cada tratamiento es alto, donde el costo medio es de $\$ 4408$ dólares, y el rango es de $\$ 1900$ - $\$ 59799$ dólares [32] 
El Activador de Plasminógeno tisular (tPA), descompone enzimáticamente los coágulos. Este tratamiento es uno de los mas utilizados a nivel mundial. Sin embargo, el tPA está sujeto a numerosas restricciones que limitan su uso únicamente en el $4 \%$ de los pacientes con EVC [4].

Las intervenciones endovasculares que utilizan dispositivos intra-arteriales, también se pueden realizar para tratar los casos de EVC isquémico o hemorrágico pero son apropiadas solo para menos del $1 \%$ de los pacientes que sufrieron EVC [6].

EL tPA es un tratamiento el cual solo puede ser aplicado hasta tres horas posteriores a los primeros síntomas del infarto y después de la confirmación de que se trata EVC isquémico; otra de sus contraindicaciones son las intervenciones quirúrgicas recientes de columna, hipertensión, uso común de anticoagulantes, administraciones de heparina hasta 48 horas de anterioridad, conteo de plaquetas menor a $100,000 / \mathrm{mm}^{3}$; así como pacientes evaluados con alta probabilidad de desarrollar infarto hemorrágico[4].

Los tratamientos invasivos como las intervenciones endovasculares, son técnicas utilizadas en centros de tratamiento de infarto, sin embargo requieren de una alta infraestructura: quirófano, TAC, RM, Unidad de Cuidados Intensivos (UCl) y endoscopio; Así como personal que requiere estar altamente especializado. Las contraindicaciones para este tratamiento son: hipertensión, obesidad, confirmación del área de oclusión y operaciones cardiovasculares recientes[5].

El propósito principal de los tratamientos anteriormente descritos es la restauración del Flujo Sanguíneo Cerebral (FSC). En trabajos anteriores se ha demostrados que una de las técnicas utilizadas para el incremento del FSC es la 
Estimulación Magnética Transcraneal (TMS)[7]. En particular la estimulación del nervio facial ha demostrado que existe un incremento en el FSC, y ha sido estudiado con fines de mostrar las ventajas que representa el uso de TMS con respecto a otras técnicas como la Estimulación Eléctrica (ES). En la tabla 1 se resumen los resultados hallados por diversos grupos de investigación.

Los hallazgos encontrados de los diversos grupos de investigación se resumen en los siguientes enunciados:

- TMS es comparable con ES

- TMS es de un uso mucho más sencillo que otras técnicas

- TMS permite despolarización del tejido nervioso con ciertos parámetros

- TMS aplicado a nervio facial en pacientes con espasmo hemifacial no tiene efectos debidos a la estimulación. 
Ing. Andrea García Quintanar

UAM-Iztapalapa

Tabla1. Tabla que muestra el resumen de los hallazgos de realizar TMS en nervio facial.

\begin{tabular}{|c|c|c|c|c|}
\hline Autor & Tipo de Sujetos & $\begin{array}{c}\text { Lugar de } \\
\text { Estimulación (E) } \\
\text { y Medición (M) }\end{array}$ & $\begin{array}{l}\text { Equipo de } \\
\text { Medición }\end{array}$ & Hallazgos \\
\hline $\begin{array}{l}\text { Verneri F, } \\
\text { Maggio F y } \\
\text { cols. [38] }\end{array}$ & $\begin{array}{l}29 \text { Humanos/ } \\
\text { Normales }\end{array}$ & $\begin{array}{l}\text { E: M1 Hemisferio } \\
\text { dominante. } \\
\text { M: Corteza motor } \\
\text { primaria }\end{array}$ & $\begin{array}{c}\text { Doppler } \\
\text { Transcranial }\end{array}$ & $\begin{array}{l}\text { La alta frecuencia de } \\
\text { TMS reduce la reacción } \\
\text { vasomotora como } \\
\text { resultado de un efecto } \\
\text { secundario del control } \\
\text { autonómico de la } \\
\text { hemodinámica cerebral }\end{array}$ \\
\hline $\begin{array}{l}\text { Hohmann D, } \\
\text { De Meester } \\
\text { C. y cols.[39] }\end{array}$ & $\begin{array}{c}20 \text { Humanos/ } \\
\text { neuroma acústico }\end{array}$ & $\begin{array}{c}\text { E: Tronco } \\
\text { Cerebral antes } \\
\text { del canal auditivo } \\
\text { M: Corteza motor } \\
\text { primaria }\end{array}$ & EEG & $\begin{array}{l}\text { TMS comparada con } \\
\text { ENOG muestra que es } \\
\text { de un } 88 \% \text { y un } 70 \% \\
\text { correspondientemente } \\
\text { la reducción de la } \\
\text { amplitud de MCS. }\end{array}$ \\
\hline $\begin{array}{l}\text { Rimpilainen I } \\
\text { Y Pyyko I. } \\
{[40]}\end{array}$ & 25 Humanos/ & $\begin{array}{c}\text { E: Fosa Posterior } \\
\text { M: Orlacularis } \\
\text { Oris Muscle }\end{array}$ & $\begin{array}{l}\text { Potenciales } \\
\text { Evocados } \\
\text { Motores } \\
\text { (MEP) }\end{array}$ & $\begin{array}{l}\text { TMS induce activación } \\
\text { del nervio facial y de } \\
\text { acuerdo a MEP el lugar } \\
\text { de activación es dentro } \\
\text { del conducto auditivo } \\
\text { interno. }\end{array}$ \\
\hline $\begin{array}{l}\text { Tokimura, } \\
\text { Hiroshi, } \\
\text { Yamagami } \\
\text { [41] }\end{array}$ & $\begin{array}{l}5 \text { Humanos/ } \\
\text { Espasmo } \\
\text { Hemifacial }\end{array}$ & $\begin{array}{c}\text { E: Región Parieto } \\
\text { Occipital } \\
\text { M: Musculus } \\
\text { nasalis }\end{array}$ & MEP & $\begin{array}{l}\text { TMS es mas cómodo } \\
\text { en su aplicación, } \\
\text { muestra resultados } \\
\text { similares ala } \\
\text { estimulación eléctrica y } \\
\text { TMS permite la } \\
\text { despolarización del } \\
\text { nervio intratemporal } \\
\text { proximal. }\end{array}$ \\
\hline $\begin{array}{c}\text { Maccabee P, } \\
\text { Amassian V } \\
\text { y cols. [42] }\end{array}$ & $\begin{array}{l}5 \text { Humanos/ } \\
\text { Normales }\end{array}$ & $\begin{array}{c}\text { E: Ipsi lateral } \\
\text { nasal } \\
\text { M: Área Parieto } \\
\text { Occipital }\end{array}$ & MEP & $\begin{array}{l}\text { TMS resulta ser útil en } \\
\text { el diagnostico de } \\
\text { parálisis de Bell y otras } \\
\text { lesiones del nervio } \\
\text { facial }\end{array}$ \\
\hline
\end{tabular}




\subsection{ESTIMULACIÓN MAGNÉTICA TRANSCRANEAL}

La Estimulación Magnética Transcraneal (TMS, por sus siglas en inglés) es una técnica de neuroestimulación y neuromodulación basada en el principio de la inducción electromagnética en tejido nervioso. Este campo magnético puede tener la magnitud y densidad suficiente para provocar la despolarización o hiperpolarización de las neuronas [9] (ver figura 3 y 4), es decir, cuando se aplica un tren de pulsos electromagnéticos se puede modular la excitabilidad cortical, incluso después del tiempo de estimulación $[7,8,9]$.

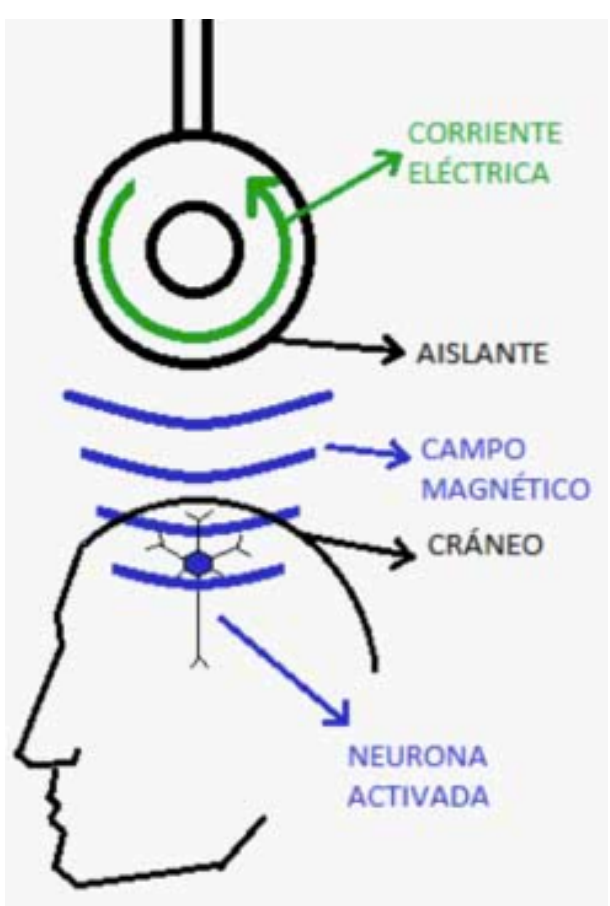

Figura 3. Principio de la TMS

Principio de la TMS el flujo que se genera la antena se convierte en un campo magnético para provocar la inducción del campo eléctrico, que estimula la actividad neuronal.

Imagen tomada de Universidad de la Laguna $\mathbb{R}, 2012$.

Los efectos de la excitabilidad cortical han traído como consecuencia la aplicación de TMS en tratamientos para diversas patologías como lo son:

- Desordenes psiquiátricos: depresiones, manías, bipolaridad, esquizofrenia, entre otros. 
Ing. Andrea García Quintanar

UAM-Iztapalapa

- Desordenes neurológicos como: Parkinson, distonía, epilepsia, tinnitus, tartamudeo.

- Rehabilitación: afasia, rehabilitación después de EVC, dolor neuropático y migrañas.

La TMS puede ser aplicada en espiga pero cuando se aplica un tren de pulsos es llamado Estimulación Magnética Transcraneal repetitiva (rTMS). La TMS es un estimulo espiga o de un pulso, donde esta puede despolarizar neuronas y provocar efectos mesurables. Por otro lado la rTMS “...puede modificar la excitabilidad de la corteza cerebral del lado estimulado así como de áreas remotas que se encuentren a lo largo de las conexiones nerviosas excitadas..."[7]. La frecuencia de estimulación es usualmente clasificada en "rápida" o "alta frecuencia" (más de $1 \mathrm{~Hz}$ ) y en "lenta" o "baja frecuencia" (menos de $1 \mathrm{~Hz})[7]$.

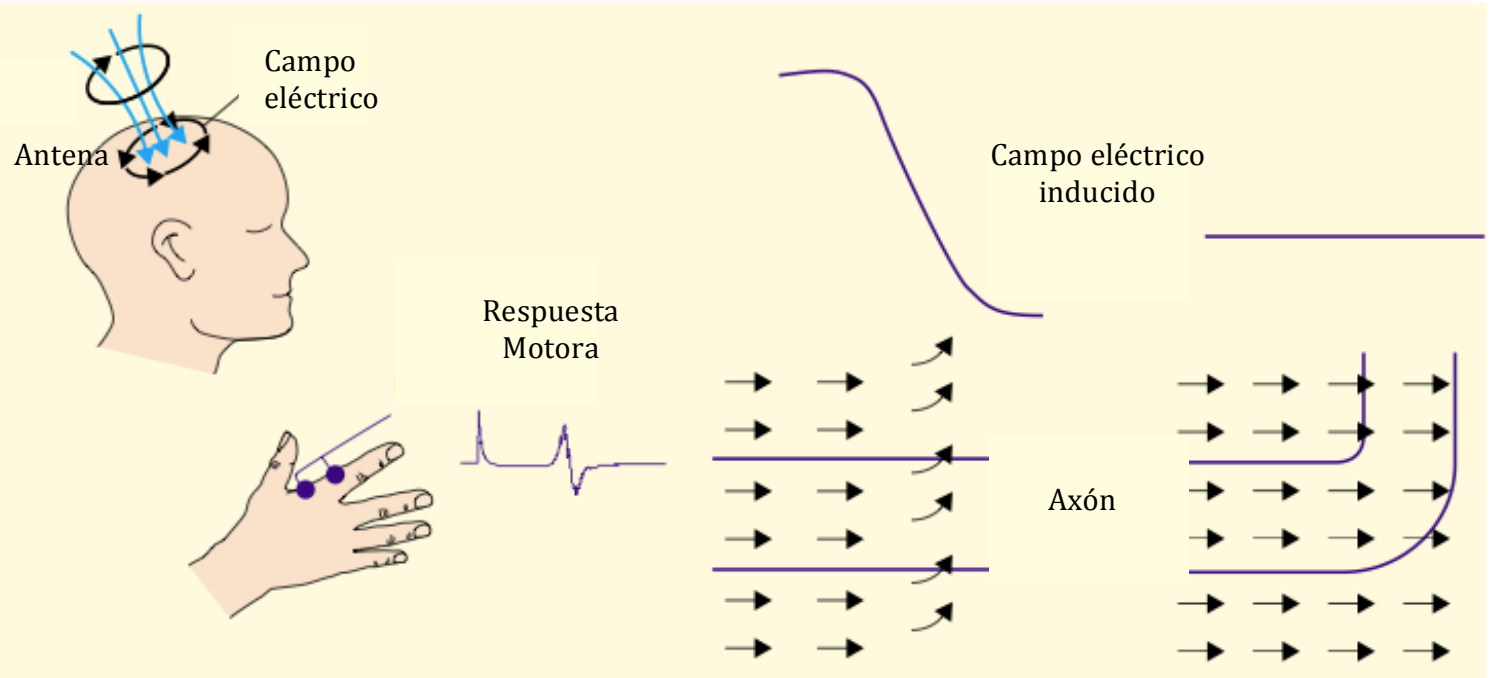

Figura 4. Figura que explica la inducción del campo eléctrico en tejido nervioso debido a TMS

Izquierda: El flujo generado en la bobina genera un campo magnético que induce una corriente eléctrica en el tejido, dicha corriente es de forma opuesta a la dirección del campo magnético. En medio: Esquema del flujo de la corriente que induce un campo eléctrico y que genera cambios a lo largo de la fibra. Derecha: Un nervio curvilíneo y una corriente uniforme en el campo eléctrico las cuales se unen en la corriente transmembranal.

(Kobayashi, 2003). 
La relación que tiene la frecuencia de estimulación con los tejidos se explica con la ley de Faraday en donde por inducción electromagnética, el campo magnético induce un campo eléctrico cuya magnitud es proporcional a la tasa de cambio del campo magnético, en donde en el caso de TMS es determinada por el cambio de la corriente en la antena. En la clínica los estimuladores y antenas usualmente utilizadas son entre 1.5 y 2.0 Tesla $(T)$, el cambio producido de corriente es por arriba de $170 \mathrm{~A} / \mu \mathrm{s}$ e induce un campo eléctrico en la corteza de $150 \mathrm{~V} / \mathrm{m}$, lo cual tiene una penetración entre $1.5-3 \mathrm{~cm}[8]$. Donde todos los parámetros son ajustables de acuerdo al objetivo de la investigación.

Los tejidos usualmente expuestos a TMS son tejidos nerviosos y huesos. En cráneo usualmente la consistencia es doblemente densa que otros huesos por lo tanto es poco conductivo y tiene un comportamiento eléctrico de un pequeño capacitor y no al de una resistencia [9].

La descripción de la aplicación de TMS en tejidos nerviosos es basada en la geometría de la antena de estimulación y en el tiempo de paso de la corriente. Los nervios usualmente se modelan de acuerdo a la capacitancia y conductancia de su membrana.

Los modelados electrónicos que explican los tejidos nerviosos pueden ser: por modelado de cable pasivo o bien por Hodkin-Huxley. El modelado de cable pasivo supone tres argumentos: 1) el potencial intracelular es solo una función de la distancia, 2) el axoplasma se comporta de forma lineal y 3) el potencial extracelular es despreciable. El modelado de Hodkin-Huxley, asume una membrana activa, en donde se tienen canales iónicos dependientes de voltaje y de conductancias[45]. En la figura se ilustran ambos modelos. 
Ing. Andrea García Quintanar

UAM-Iztapalapa

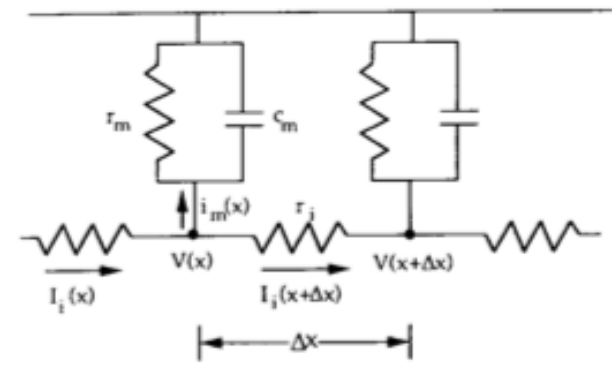

(a)

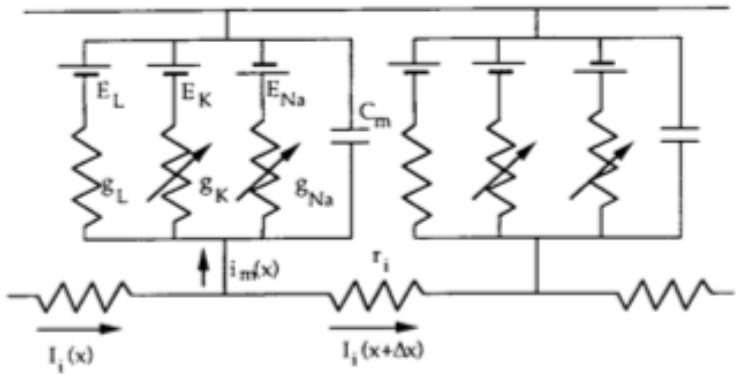

(b)

Figura 5. Figura que muestra el modelo electrónico de los nervios. a) modelo de cable pasivo, b)Modelo de Hodkin-Huxley.

En a) podemos observar que el modelo pasivo contempla la resistencia del espacio intracellular como ri, y la Resistencia de la membrane como rm. En b) el modelo e Hodking-Huxley representa a la membrane con tres fuentes de voltaje variables y conductancias dependientes del tiempo. (Bradley, 1990)

Donde el desarrollo de las ecuaciones que describen el circuito, en cada uno de los modelos es de acuerdo a la notación de Bradley[45].

Por otro lado la bobina que induce el campo magnético trabaja bajo las leyes de Faraday, el circuito que modela de forma mas básica un equipo de TMS esta compuesto por al menos un condensador, un circuito de carga y de descarga[46].

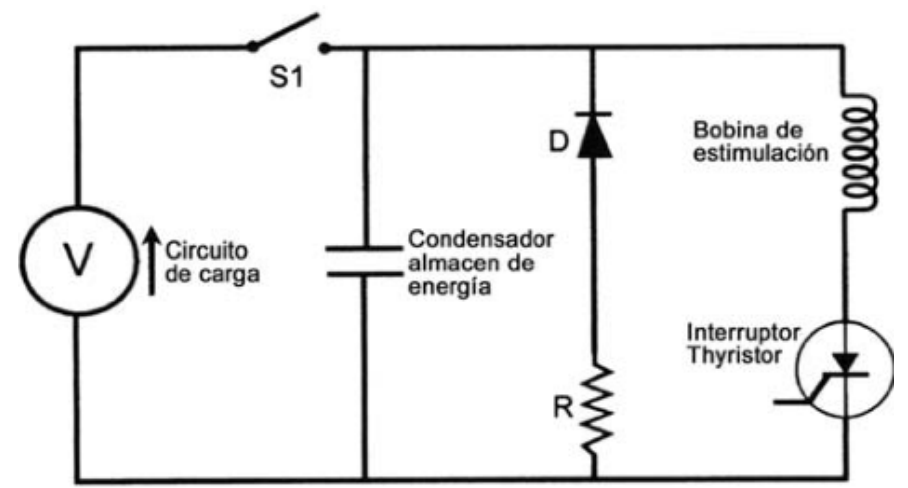

Figura 6. Modelado básico de un sistema de TMS. (Pascual, 2008) 
La ley de Faraday describe cuantitativamente el fenómeno del campo magnético y del campo eléctrico dependientes del tiempo. Según sus hallazgos, la variación del flujo magnético en algún circuito produce una corriente inducida (Fuerza Electromotriz, FEM )[47].

Dicha ley esta descrita de la siguiente forma:

$$
\varepsilon=-\frac{\mathrm{d} \Phi_{\mathrm{B}}}{\mathrm{dt}}
$$

donde

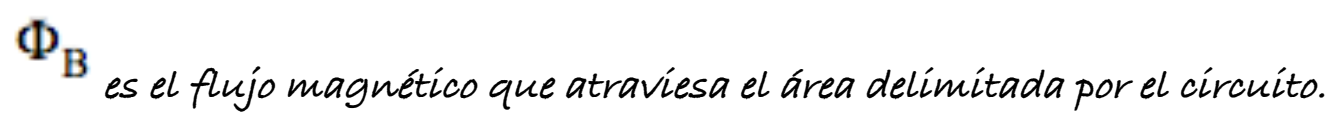

La FEM inducida está definida como la circulación de este campo a lo largo del contorno:

$$
\varepsilon \equiv \oint_{C} \mathbf{E} \cdot \mathrm{d} \mathbf{l}
$$

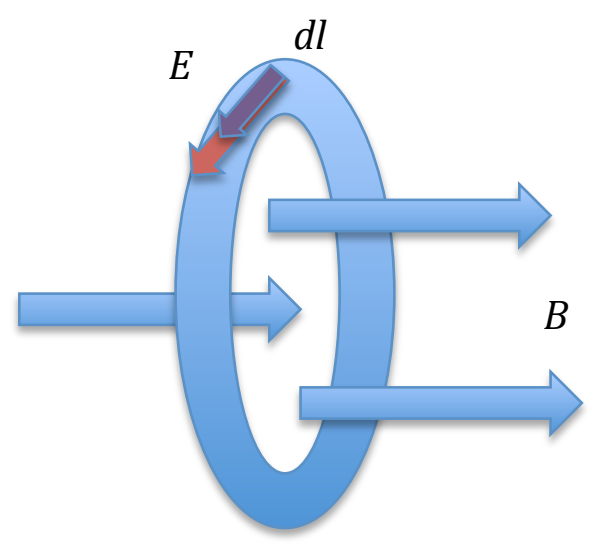

Figura 7. Ilustración del comportamiento de inducción electromagnética 
Ing. Andrea García Quintanar

UAM-Iztapalapa

En las ecuaciones del campo magnético y de la FEM podemos observar que existe una relación directa entre ellas. Lo anterior fue observado por Faraday y se logro describir una relación integral entre los campos eléctricos y magnéticos. Esta relación se describe en la siguiente ecuación:

$$
\oint_{C} \mathbf{E} \cdot \mathrm{d} \mathbf{l}=-\frac{\mathrm{d}}{\mathrm{dt}} \int_{S} \mathbf{B} \cdot \mathrm{d} \mathbf{S}
$$

Donde S, es la superficie sobre la cual se calcula el flujo, dicha superficie estará delimitada por el contorno $\mathrm{C}$.

Con los conceptos de inducción electromagnética y los modelos de nervio, podemos introducir las ecuaciones de Maxwell que describen la relación entre estos dos. Sin embargo se tienen que considerar que no existe la propagación electromagnética en el entorno. Cohen [48] determina que el campo eléctrico inducido puede ser expresado como el producto de una función de tiempo y espacio. Sin embargo la literatura [46] menciona la problemática de que al existir dos tipos de tejido en donde su conductancia y resistencia es diferente, esto producirá un gran impacto en la magnitud del campo eléctrico. A demás de que la localización y el tiempo de estimulación depende de los componentes mencionados como lo son: la localización del nervio, la posición y geometría de la bobina, y la resistencia de los tejido[45].

Los estudios reportados en la literatura indican que la medición de los efectos de TMS se realizan principalmente por medio de Doppler Transcraneal y Electro Encefalograma (EEG) $[9,19]$. Sin embargo también se reporta que se han tenido dificultades al obtener mas datos y que los equipos han tenido problemas de interferencias con el estimulador $[9,10]$.

Dentro de la literatura, el lugar de estimulación es crucial al momento de la medición del efecto de la TMS[10]. En perros y ovejas normales bajo anestesia, 
la estimulación se enfocó en el segmento temporal del nervio facial, mostrando que usando técnicas para la medición de perfusión, como lo son Doppler y RM, la respuesta del incremento o decremento de la perfusión depende de la estimulación realizada (potencia, frecuencia y localización). Los experimentos evaluados por medio de RM han mostrado ser reproducibles y lo suficientemente sensibles a la medición de los cambios de perfusión[11,12].

\subsection{NERVIO FACIAL}

El nervio facial o VII par craneal es un nervio mixto, fibras eferentes ( motor y vegetativo) y fibras aferentes (sensitivo y sensorial). Nace en tallo cerebral justo entre el puente troncoencefálico y el bulbo raquídeo. Controla los músculos de expresión facial así como el sabor en los dos tercios anteriores de la lengua. También suple inervación preganglionar parasimpática a varios ganglios nerviosos de la cabeza y el cuello[33].

Uno de sus segmentos es el intracanalicular, en este las fibras motoras y las glosopalatinas están agrupadas en la parte aterior-superior del canal auditivo interno (CAI) donde las fibras motoras cubren las fibras sensitivas e invaginan en el ganglio geniculado[34].

El ganglio geniculado esta localizado en el hueso petroso[35]. Inerva con fibras somáticas y componentes parasimpáticos del nervio facial y envía fibras que inervan en la glándula lagrimal, glándula submandibular, glándula sublingual, lengua, paladar, faringe, meato auditivo externo, estapedio, vientre posterior del músculo digástrico, músculo estilohioídeo y músculos de la expresión facial. Así mismo una de las conexiones es con el contingente simpático que es derivado del par craneal IX para formar el nervio del conducto pterigoideo [35]. 
Ing. Andrea García Quintanar

UAM-Iztapalapa

La conexión que el ganglio geniculado establece con el par craneal IX (nervio glosofaríngeo) permite hacer una sinergia con el par craneal $X$ ( nervio vago). El nervio vago contiene fibras mixtas donde actúan nervios parasimpáticos y es donde finalmente el sistema nervioso parasimpático se ve involucrado[34].

El sistema nervioso parasimpático es sensible a la estimulación del nervio vago, en donde, dependiendo del tipo de estimulación este se puede activar o desactivar dando paso a la acción del sistema nervioso simpático[36]. 

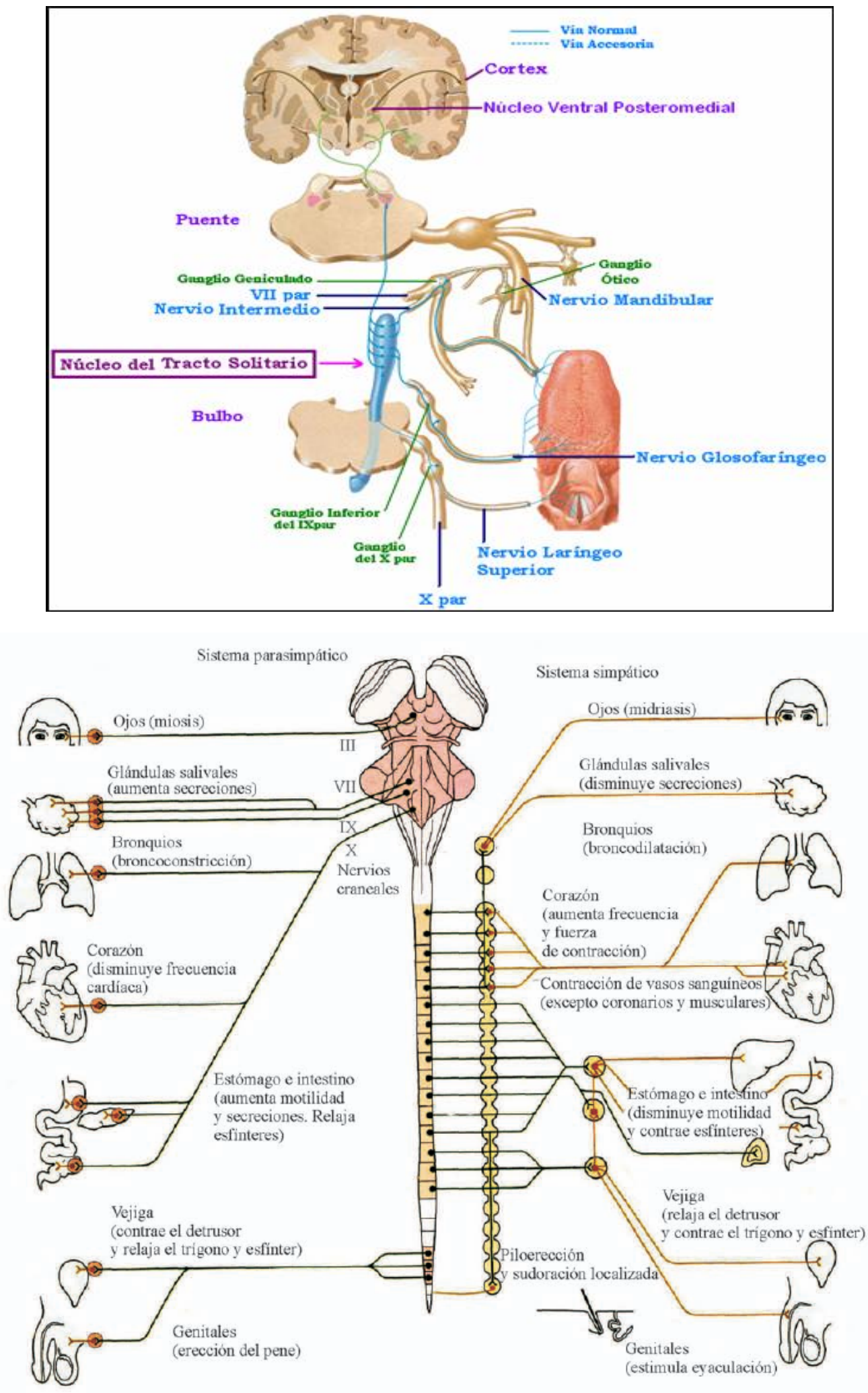

Figura 8 : Figura que muestran la localización anatómica de el nervio facial y sus conexiones así como la localización del ganglio geniculado.

Arriba: Imagen que muestra la anatomía del nervio facial así como sus conexiones con el par craneal IX, y la localización del ganglio geniculado. Abajo: Conexiones de algunos pares craneales con los órganos así como su acción de acuerdo al sistema nervioso simpático y parasimpático.

Imágenes tomadas de Universidad de la Frontera, 2013. 
Ing. Andrea García Quintanar

UAM-Iztapalapa

\subsection{RESONANCIA MAGNÉTICA NUCLEAR}

La Resonancia Magnética Nuclear (RMN) es una poderosa técnica de investigación de propiedades químicas y físicas a nivel molecular. La RMN se puede explicar cómo la interacción que tienen las partículas que poseen una propiedad llamada "spín", con un campo magnético externo (B0). Este fenómeno fue descubierto por Bloch y Purcell en 1946[12].

La RMN mide la absorción de la radiación electromagnética de $4-900 \mathrm{MHz}$ en la cual participan los núcleos de los átomos de hidrogeno. Para que en los núcleos se formen estados de energía que hagan posible la absorción, es necesario colocar la muestra para análisis en un intenso campo magnético.

En la mecánica clásica, un objeto que tiene un movimiento circular con cierta frecuencia produce un momento angular $(p)$ perpendicular al plano donde se mueve. Si suponemos que este objeto tiene carga eléctrica, y que crea una corriente eléctrica; ésta corriente genera un momento magnético $(\mu)[44]$.

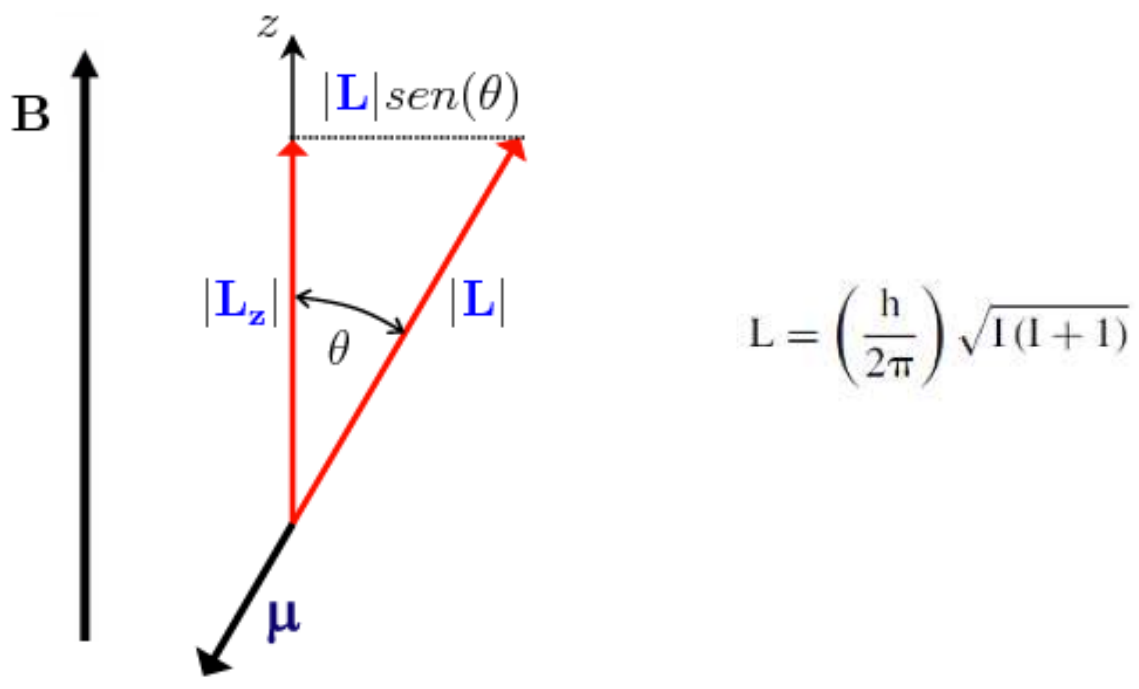

Figura 9. Figura que muestra el momento angular del protón. 
El protón tiene una frecuencia giromagnética fundamental en su estado libre. Cuando se introduce dentro de un campo magnético externo (B0) lo suficientemente intenso para cambiar la frecuencia de su momento magnético, el protón sufre un cambio de frecuencia. A este efecto se le conoce como precesión a la frecuencia de Larmor:

donde:

$$
\omega_{0}=\gamma B_{0}
$$

$\omega_{0}=$ frecuencia de Larmor $[\mathrm{MHz}]$

$\gamma=$ razón giromagnetica del protón de Hidrógeno [42.58 MHz/T]

$$
B_{0}=\text { intensidad del campo externo }[T]
$$

Sin embargo cuando se utiliza la frecuencia de Larmor para generar un campo magnético (B1) en una dirección diferente a B0 el núcleo al someterse a B1, se vera forzado a seguir la dirección de este nuevo campo. Cuando el protón se encuentra en este nuevo campo tendremos un fenómeno llamado magnetización transversal o Mxy. Esta señal será recibida por la antena. Sin embargo, B1 es temporal y cuando desaparece, el protón buscara regresar a su estado basal, que será la dirección de B0. Entonces será medido el proceso por el cual llega a su posición original. Dos procesos son los que se ven involucrados: la relajación longitudinal (T1) y la relajación transversal (T2). A este efecto se le conoce como el Decaimiento de Inducción Libre (FID, por sus siglas en inglés).

En la siguiente imagen se muestra el diagrama de flujo que se ve involucrado en la RMN así como los dos principales productos: Imagenológia por Resonancia Magnética (IRM) y Espectroscopia por Resonancia Magnética (ERM). 
Ing. Andrea García Quintanar

UAM-Iztapalapa

CAMPO MAGNÉTICO

RADIOFRECUENCIA

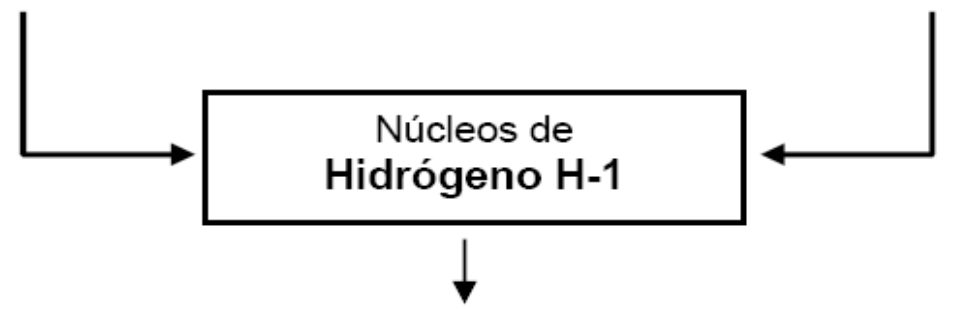

Absorción energética: RESONANCIA

Imagen (IRM)

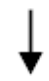

Liberación energética: RELAJACIÓN

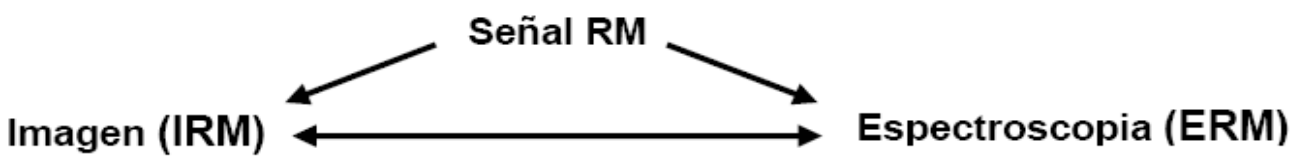

Figura 10. Figura que muestra el diagrama general de la generación de señales de la resonancia magnética

En la figura se puede observar que la interacción del campo magnético y de la radiofrecuencia con los núcleos de Hidrogeno, provocan los efectos de resonancia y relajación(T1, T2), donde dicha señal al ser tratada con análisis de Fourier se genera imagines o señales de espectroscopia.

Una de las aplicaciones más importantes de la RMN es la obtención de imágenes en sistemas biológicos in vivo. Los datos de excitación de las moléculas (principalmente protones de Hidrógeno) de objetos sólidos 0 semisólidos con pulsos de radiofrecuencia se someten a una transformación de Fourier y se convierten en imágenes bidimensionales del interior del objeto.

La calidad de las imágenes de resonancia depende de varios parámetros como los tiempos de relajación $\mathrm{Tl}$ y T2, la densidad de los núcleos resonantes y la actividad de las particulas en la estructura molecular de la muestra estudiada, así como las secuencias de pulsos y los tiempos de eco, entre otros[49].

Los tiempos de relajación TI y T2, son fundamentalmente los tiempos en que se mide la rapidez de recuperacion de los spines después de ser sometidos a 
perturbaciones por señales de radiofrecuencia. Estos tiempos de relajación (o de cualquier núcleo resonante) son completamente dependientes del resto de los átomos que los rodean, ya que estos modifican sus características de movimiento físico en relación con su entorno, midiéndose mediante el tiempo de relajación longitudinal (T1) y el tiempo de relajación transversal (T2).

El tiempo de relajación T1 corresponde al tiempo que se requiere para lograr una realineación del spin con el campo magnético externo. Es decir, es el tiempo en que tarda el componente longitudinal en llegar al 63\% de su valor inicial. T1 informa que tan rápido el movimiento del spin puede emitir la energía absorbida al medio circundante. Este tiempo es dependiente y específico al tipo de tejido en el que se encuentren inmersos los protones. La relajación longitudinal tiene la forma de una exponencial creciente regulada por una constante de tiempo llamada T1 (ms), que caracteriza su recuperación.

El tiempo de relajación T2 se refiere al decaimiento de la magnetización transversal que acompaña a la recuperación de la magnetización longitudinal (durante T1) y está determinado por la interacción entre protones, en el cual, los spines se anulan entre ellos al desfasarse. T2 se define entonces como el tiempo en que tarda la componente transversal en decaer al $37 \%$ de su valor inicial y es también dependiente y específico del tipo de tejido en el que se encuentran inmersos los protones.

Existen varios parámetros técnicos con los que se planean las secuencias pueden modificarse para lograr un contraste diferente entre los tejidos, es decir, información acerca de su T1 o de su T2. Los más comúnmente manipulados son: el tiempo de repetición (TR), el tiempo de eco (TE) y el ángulo de deflexión de la magnetización $(\phi)$. 


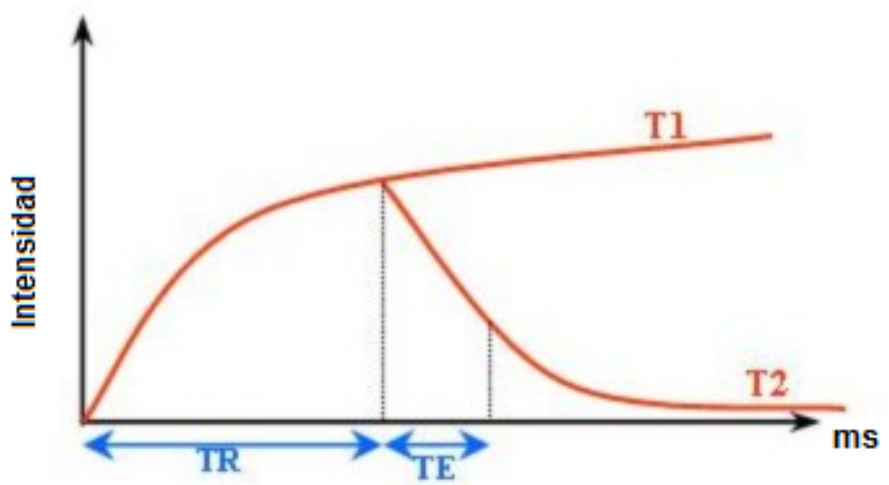

Figura 11. Grafica del comportamiento de T1 y T2

Relacion y comportamiento entre T1 y T2, y los tiempos de repeticion (TR) y de eco (TE).

(Galvez, 2005)

Una de las ventajas del uso de IRM en el ámbito clínico en comparación con otras técnicas imagenológicas es la no exposición del sujeto a radiación ionizante, además de que puede proveer imágenes de alta resolución y con diferentes tipos de contraste.

Es por estas características que la IRM ha tenido un gran impacto clínico y en la investigación. Dentro de las guías clínicas para el diagnóstico y tratamiento del EVC se menciona que el uso de la IRM puede reemplazar las imágenes obtenidas en TAC; por lo contrario un estudio de TAC siempre debe de ser complementado por estudios de MRI, según el protocolo dictado por "American Stroke Association", en los Estados Unidos[14].

En los protocolos imagenológicos de resonancia magnética para la detección de EVC, se utilizan secuencias spin-eco, debido a su sensibilidad y especificidad al momento de la diferenciación de tejidos (sanos, hemorrágicos, cancerígenos, etc). Las secuencias utilizadas son típicamente: T1 ponderado (T1-W), T2 ponderado (T2W), Eco Spin Rápido (FSE), Inversión Recuperación (IR), Atenuación de Fluidos con Inversión Recuperación (FLAIR), T2 gradiente eco (T2 gradient echo) y T1 contrastado [1]. Adicionalmente, se pueden aplicar otras 
técnicas de IRM que proporcionan distintos tipos de información.

Las angiografías por RM (ARM) son imágenes que permiten la visualización vascular del área en donde se esta realizando el estudio. La ARM es un estudio que en comparación con las angiografías normales no requiere de medio de contraste. Normalmente son indicadas para la detección de las oclusiones intravasculares.

La difusión por RM es una técnica que se basa en el movimiento Browniano de las moléculas de agua[15], que en EVC hemorrágico provoca un exceso de agua en el liquido intracelular o edema citotóxico. En este tipo de imágenes el tejido isquémico aparece brillante en comparación con tejido normal. Las imágenes obtenidas para la medición de difusión nos brindan la posibilidad de realizar mapas de Coeficiente de Difusión Aparente (CDA), sin embargo se reporta que su visualización puede ser hasta cuatro o cinco horas después del EVC. EI CDA se va incrementando a los tres o cinco días y vuelve a su estado basal de una a cuatro semanas[15].

La medición de la Perfusión por RM (PRM) usa secuencias de Imagenología Eco Planar (EPI) para su obtención y se utiliza para la identificación de áreas de isquemia reversible (penumbra). El principio de la PRM es que al pasar un agente de contraste a través de los capilares cerebrales, este causa una perdida de la señal de forma temporal. Por lo tanto la técnica implica una forma hemodinámica tiempo-señal de la curva. En la figura 3 se describe la curva formada por PRM[16].

Existen otras técnicas que usualmente no son usadas para protocolos de

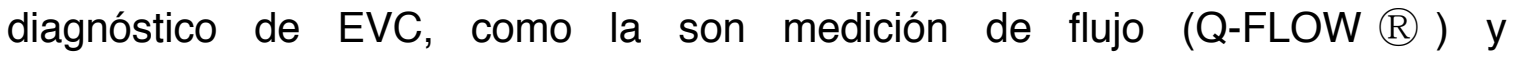
espectroscopia por resonancia magnética (ERM).

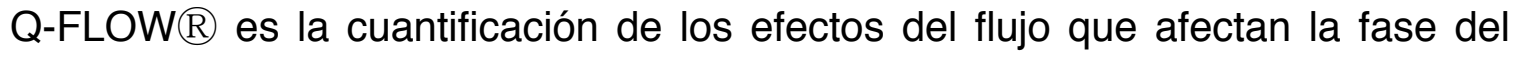
spin, por lo cual mide la diferencia de los "tejidos" en movimiento con respecto a 
Ing. Andrea García Quintanar

UAM-Iztapalapa

los estacionarios. Esta técnica sirve para calcular un mapa de velocidades o flujos medidos en el tiempo y en el mismo plano. Una vez que se adquieren secuencias de flujo, se hace una substracción de fase, esto crea un Diagrama de Intensidad-Tiempo (TID, por sus siglas en ingles) para que se calcule el flujo en mililitros por segundos $(\mathrm{ml} / \mathrm{s})$ o la velocidad en centímetros por segundo $(\mathrm{cm} / \mathrm{s})$. Dentro del software utilizado para un post-procesamiento se requiere la utilización de una Región de Interes (ROI, por sus siglas en ingles) en donde el resultado es la suma de los desplazamientos de la fase que comprende la $\mathrm{ROI}$ normalizado con el tamaño de la ROI, es decir la media del flujo o velocidad[37]

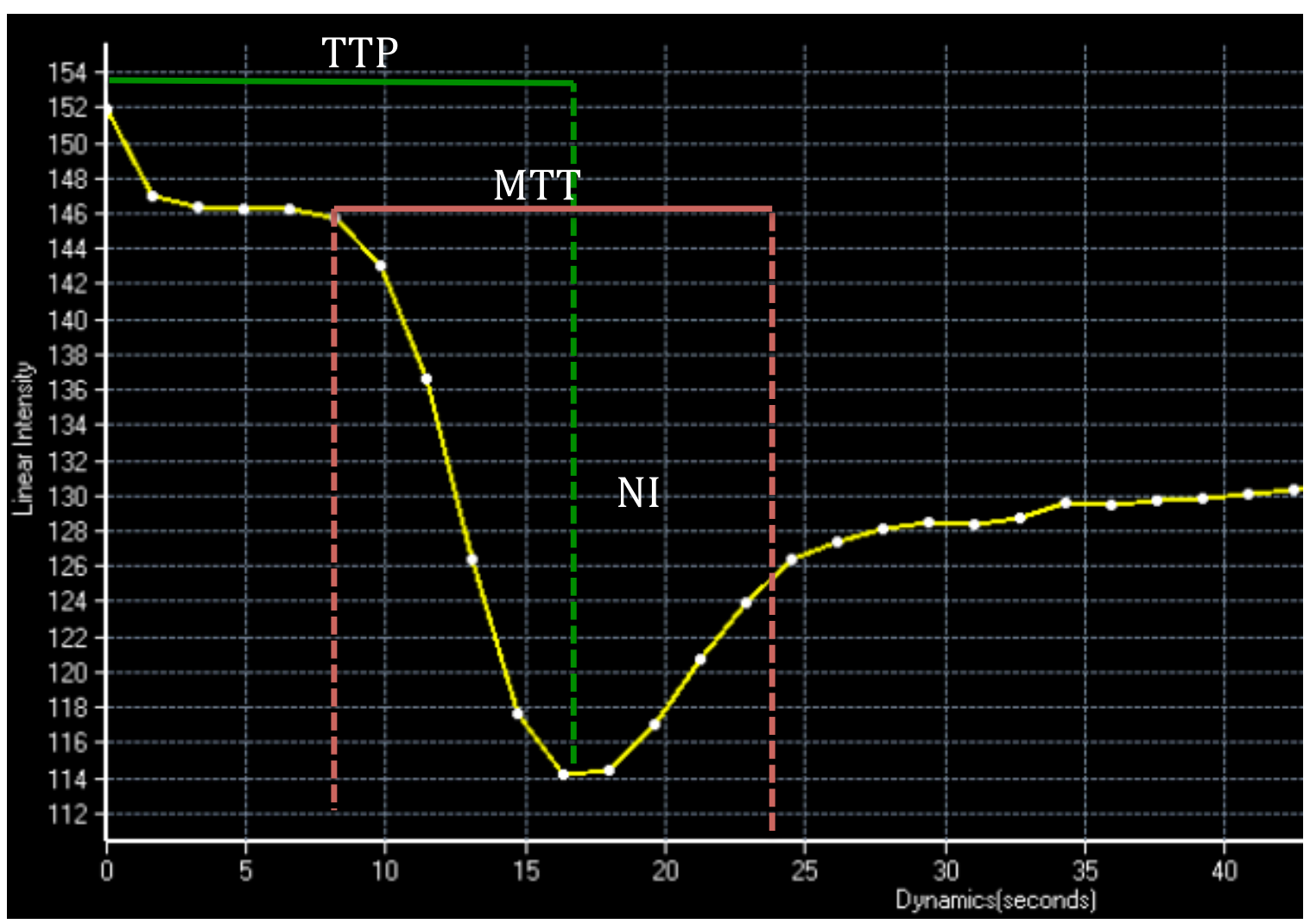

Figura 12. Grafica de perfusión por RM.

Grafica resultante de la perfusión por Resonancia Magnética. En el eje de las abscisas tenemos las secuencia dinámicas en segundos, en el eje de las ordenadas la intensidad lineal. En donde TTP-Tiempo al pico, es el tiempo del inicio del scan hasta la máxima atenuación, MTT-Media del tiempo, es el tiempo que le toma al bolo de contraste pasar desde la arteria hasta la circulación venosa. NI es el área de MTT que se asume simétrica y es una medida relativa del flujo cerebral. 


\subsection{ESPECTROSCOPÍA POR RESONANCIA MAGNETICA (ERM)}

Una ERM puede ser realizada sobre distintos núcleos, como lo son el Hidrogeno $\left({ }^{1} \mathrm{H}\right)$, Carbon- $13\left({ }^{13} \mathrm{C}\right)$, Fósforo $\left({ }^{31} \mathrm{P}\right)$ y sodio $\left({ }^{23} \mathrm{Na}\right)$. Cada uno de estos aporta información relevante de acuerdo a lo que se busca observar. Para cada núcleo es posibles detectar una cantidad importante de metabolitos de forma simultanea. El ${ }^{31} \mathrm{P}$ nos brinda información acerca de metabolitos energéticos importantes, tales como: $\mathrm{pH}$ intracelular y concentración de magnesio principalmente. Además es importante mencionar que esta técnica es posible llevarla a cabo in vivo lo cual nos permite hacer estudios del mismo sujeto en el tiempo[12].

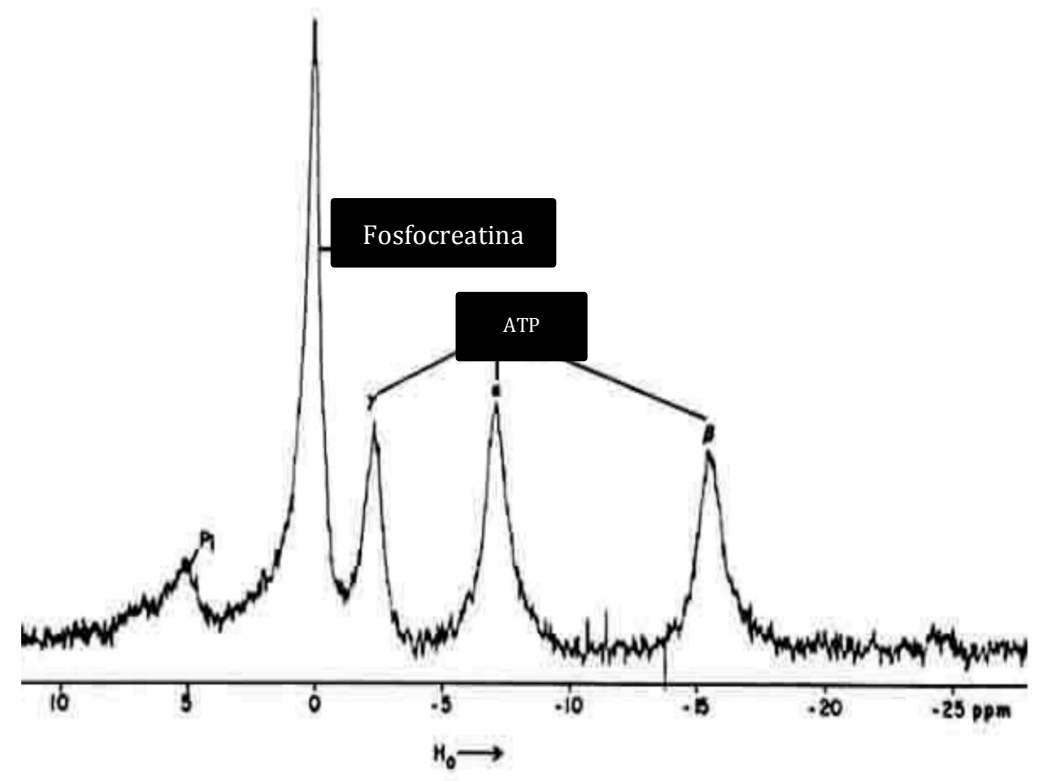

Figura 13. Localización de los principales metabolitos de ${ }^{31} \mathrm{P}$

Localización típica de principales metabolitos de espectroscopia por Resonancia Magnética de $31 P$, en cerebro de rata.

(De Graff, 1998) 
Ing. Andrea García Quintanar

UAM-Iztapalapa

Dentro de los metabolitos que el ERM de ${ }^{31} \mathrm{P}$ es capaz de detectar se encuentran los picos de Adenosin Trifosfato (ATP), alfa $(\alpha)$, beta ( $\beta$ ) y gamma ( $\mathrm{y}$, localizándose a -7.52, -16.26 y -2.48 ppm correspondientemente, por otro lado la detección del pico de Pi, localizado a 5.02 ppm. En la figura cuatro se muestra la posición de los picos anteriormente mencionados.

Independientemente de la resonancia del pico de fosfocreatina (PCr), la resonancia del ATP es también sensible a los enlaces de las valencias de los cationes, especialmente a los del Magnesio $\left(\mathrm{Mg}^{2+}\right)$. Las resonancias $\beta Y_{\gamma}$-ATP muestran un cambio en su desplazamiento químico cuando las concentraciones de magnesio cambian. El desplazamiento químico de la resonancia de $\alpha$-ATP muestra que no existe una dependencia a los enlaces de Magnesio. En la siguiente ecuación 1 de puede ver la relación anterior:

$$
\mathrm{MgATP}^{2-} \rightleftarrows \mathrm{Mg}^{2+}+\mathrm{ATP}^{4-} \quad \text { Ecuación } 1
$$

Con la correspondiente constante de disociación:

$$
K_{D, M g A T P}=\frac{\left[\mathrm{Mg}^{2+}\right] \cdot\left[A T P^{4-}\right]}{\left[\mathrm{MgATP}^{2-}\right]} \quad \text { Ecuación } 2
$$

Sin embargo la diferencia del desplazamiento químico de las resonancias entre a y $\beta$-ATP (o y) pueden ser utilizadas para estimar la concentración de magnesio libre intracelular (CML). Siguiendo la notación de Gupta [43], la CML puede ser calculada como

$$
\left[\mathrm{Mg}^{2+}\right]=K_{D, M g A T P}\left(X_{f}^{-1}-1\right) \quad \text { Ecuación } 3
$$

donde

$$
X_{f}=\frac{[A T P]_{f}}{[A T P]_{t}} \quad \text { Ecuación } 4
$$

Donde $X_{f}$ es la relación del ATP total contra el instantáneo. 
La fracción de $X_{f}$ de ATP libre contra el total de ATP puede ser expresado en términos de la diferencia del desplazamiento químico entre las resonancias de a y $\beta$-ATP de acuerdo a:

$$
X_{f}=\frac{\Delta_{\text {invivo }}-\Delta_{M g A T P}}{\Delta_{M g A T P}-\Delta_{A T P}} \quad \text { Ecuación } 5
$$

Donde $\Delta_{\text {invivo }}$ es la observación, in vivo es la diferencia del desplazamiento químico de las resonancias de a y $\beta$ ATP. $\Delta_{\text {MgATP }}$ y $\Delta_{\text {ATP }}$ representan la misma diferencia del desplazamiento químico entre el ATP consumido y el libre, respectivamente.

\subsection{NEURONAVEGACIÓN}

Los modelos existentes abarcan gatos, ratas y borregos pero en ninguno de estos modelos se han combinado la estimulación del nervio facial y la medición de la perfusión por medio de RM. Los efectos causados por TMS resultan ser altamente sensible a la localización de la estimulación, y aunque se han demostrado los buenos resultados de la estimulación del nervio facial, es imperativo que la localización de éste sea lo mas exacto posible[18].

Una de las técnicas para lograr una buena localización es la neuronavegación. Esta es una técnica utilizada desde hace algún tiempo para la realización de procedimientos quirúrgicos neurológicos. Este es un sistema que consta del registro de imágenes tomadas con anterioridad con respecto a la nueva posición del paciente logrando con eso sincronizar en tiempo real la posición con la anatomía. Proveyendo un asistente computacional al momento de realizar algún procedimiento.

La neuronavegación facilita la localización del nervio facial (ganglio geniculado). El nervio facial es el séptimo de doce pares de nervios craneales. Este emerge 
Ing. Andrea García Quintanar

UAM-Iztapalapa

del tronco cerebral entre el puente de Varolio y la medula, y controla los músculos de las expresiones faciales, y las funciones de transporte de las sensaciones del gusto de los dos tercios anteriores de la lengua. También suministra fibras parasimpáticas pre ganglionares y los ganglios del cuello[18,19,20].

En la figura 14 se muestra la localización del VII par craneal. Como se observa este se encuentra muy cerca del oído y tiene grandes ramificaciones. Sin embargo se cuenta con los ganglios que sirven como conducto para la transmisión de los potenciales de acción. El ganglio geniculado esta localizado justo detrás de la cóclea.

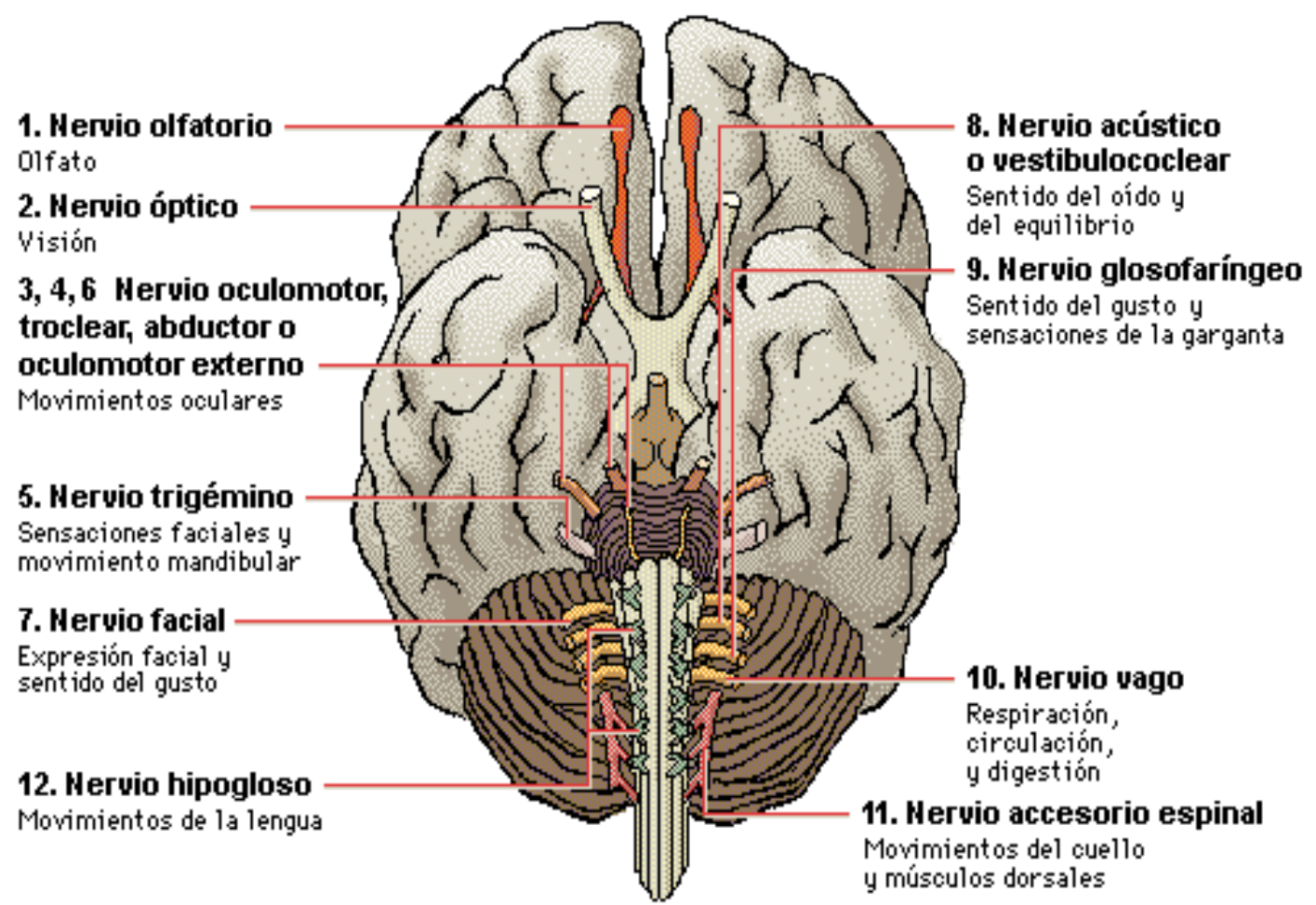

Figura 14. Localización anatómica de los pares craneales

Imagen que muestra la localización anatómica de los 12 nervios o pares craneales, así como la descripción del control de cada uno. 
Actualmente la implementación del procesamiento de imágenes y la neuronavegación en los modelos de ACV para la evaluación de nuevos sistemas de tratamiento y/o diagnóstico son importantes para encontrar nuevas formas de prolongar el tiempo para la toma de decisión de tratamiento y poder tener mayores probabilidades de recuperación [24,25].

\subsection{PROTOCOLO PILOTO DE EVC CON TMS EN OVEJAS}

\subsubsection{RECURSOS MATERIALES}

Los experimentos fueron realizados en el Centro Nacional de Investigación en Imagenología e Instrumentación Medica (Cl3M) que es un Laboratorio Nacional, financiado por partes iguales por el Consejo Nacional de Ciencia y Tecnología (CONACyT) y la Universidad Autónoma Metropolitana (UAM). Cuenta con dos laboratorios de resonancia magnética con equipos de 3T para humanos y $7 \mathrm{~T}$ para pequeñas especies; un quirófano experimental equipado para todo tipo de intervenciones en animales de experimentación, un laboratorio de instrumentación equipado para el desarrollo de sistemas y equipos y un laboratorio para radiología donde hasta hace poco se tenía la instalación de dos tomógrafos que se han dado de baja para albergar al equipo de fluoroscopía (rentado en la actualidad) y los equipos de estimulación magnética transcraneal y el sistema de neuronavegación (proporcionados por Lake Biosciences) que se han empleado para los estudios del proyecto que se presenta. Adicionalmente hay espacios para albergar a los estudiantes e investigadores del Cl3M. Todos los espacios cuentan con la protección requerida y cumplen las normas para la operación de los equipos en cuestión (protección radiológica y aislamiento electromagnético).

\subsubsection{MODELO EN OVEJAS}

Por tratarse de una propuesta de modelo animal, se escribió un protocolo para la revisión del comité de ética de la División de Ciencias Básicas e Ingeniería 
Ing. Andrea García Quintanar

UAM-Iztapalapa

(CBI). Así mismo se montaron 2 modelos en proyectos piloto con el fin de obtener resultados preliminares que sustentaran el principio de la hipótesis y con el fin de determinar cual de los modelos funcionaba mejor de acuerdo a la infraestructura material y humana con la que cuenta el CI3M.

Para la descripción del proceso metodológico en la siguiente figura se muestra un esquema general de lo que se busco para lograr la comprobación de la hipótesis

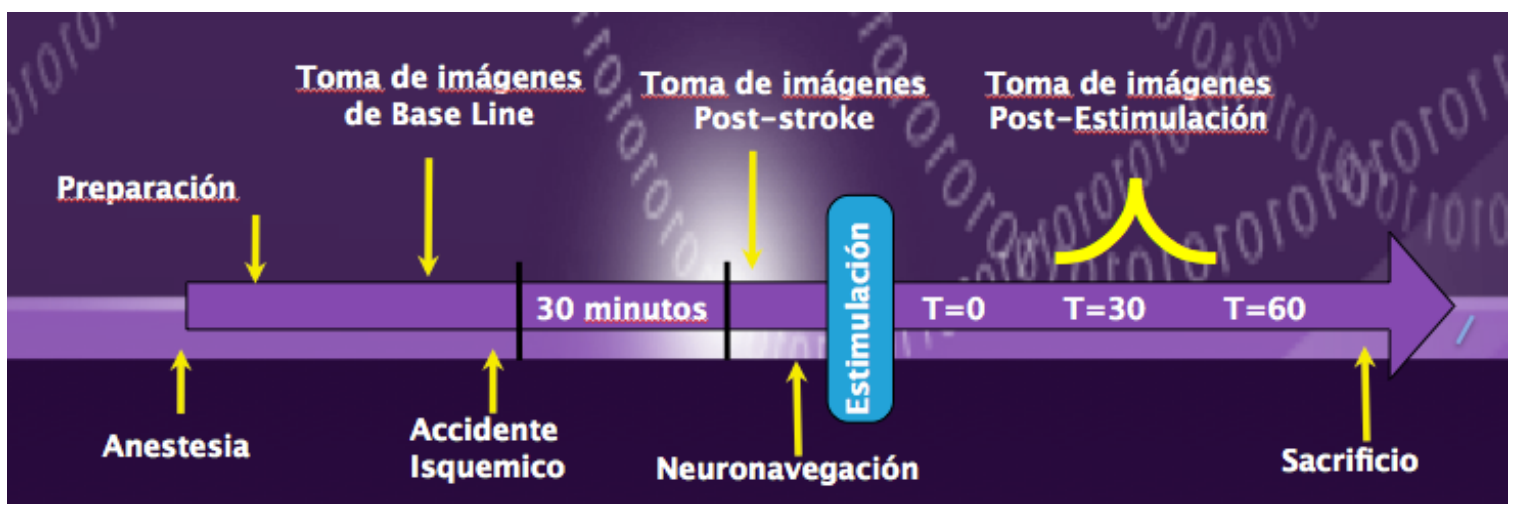

Figura 15. Línea de tiempo para el protocolo de ovejas

Imagen que muestra la línea de tiempo programada a seguir para el primer modelo montado en ovejas.

Este primer modelo animal se realizo con ovejas de raza Rambouillet. Dos ovejas de $80 \mathrm{~kg}$ fueron anestesiadas por vía arterial y estabilizadas en posición supina. Una vez preparados se transportaron al cuarto de RM.

Una de las características de las RM aprobadas por la Food Drug Administration (FDA) y demás organizaciones es el tamaño del túnel, este debe de ser de 80 cm de diámetro, así que una de las complicaciones que se presentaron en este primer modelo fue la posición adecuada para la toma de imágenes dentro del túnel de la RM. Una oveja tiene aproximadamente $100 \mathrm{~cm}$ de altura de pezuñas a orejas, y aunque se doblaron las patas para un mejor acomodamiento, este dobléz provoco oclusión de la vía intravenosa para la administración de Propofol como anestesia[25]. 
Otro de los problemas denotados en este modelo es propio de la posición en la que se encuentra el animal, por tratarse de animales rumiantes se da una acumulación de gases en la zona abdominal por lo tanto era necesario detener la secuencia de la RM para poder extraer los gases acumulados.

Por las complicaciones anteriores se decidió montar el protocolo en otro tipo de animal. Dentro de la revisión de modelos animales existentes para EVC, nos encontramos un modelo canino que ha resultado altamente repetible y de fácil manejo. 


\section{HIPÓTESIS}

Una combinación de secuencias de resonancia magnética permiten una cuantificación reproducible de los cambios en perfusión y el daño isquémico en tejido cerebral en un modelo de EVC isquémico agudo, donde se produce el EVC y el tiempo de aplicación de tratamiento no es mayor a 2 horas. Dicha combinación nos permite validar nuevos tratamientos para EVC.

- La medición de la perfusión por Resonancia Magnética es una herramienta útil y de fácil reproducción, para la corroboración del incremento de la perfusión debido a la estimulación magnética transcraneal del nervio facial.

- El flujo en las carótidas externas se ve aumentado debido al efecto de la vasodilatación por la estimulación del nervio facial y es persistente en el tiempo con respecto al grupo no estimulado.

- La medición del metabolismo a través de la relación ATP/P total revela un incremento del metabolismo post infarto y post estimulación, en comparación con el grupo control. 


\section{OBJETIVOS}

Lograr que a partir de una caracterización de la perfusión cerebral resultante de la aplicación de un tratamiento para EVC isquémico se realice una cuantificación reproducible de los daños en tejido cerebral.

- Evaluar la perfusión a través de secuencias de perfusión con medio de contraste. Los resultados esperados son la perdida de perfusión después del modelo de EVC agudo y la ganancia de perfusión después de TMS.

- Cuantificar la medición de velocidad de flujo sanguíneo en carótidas internas y externas por medio de secuencias Q-FLOW antes y después del modelo de EVC agudo, cuya medición después de TMS sustenta mejora el flujo en el modelo.

- Compulsación en ambos grupos ( estimulado y control) de la medición de ${ }^{31} \mathrm{P}$ de región isquémica a lo largo de las ventana de tiempo. 


\section{METODOLOGÍA}

\subsection{TRATAMIENTO DE LOS ANIMALES, MODELO CANINO}

Perros adultos sanos de raza mixta entre 15 y $37 \mathrm{Kg}$ fueron obtenidos del bioterio de la Benemérita Universidad Autónoma de Puebla. Los sujetos fueron seleccionados y cuidados de acuerdo a las normas mexicanas[26]. Asegurando el acceso de agua y comida ad libitum hasta 8 horas antes del procedimiento; donde comida fue restringida. La figura 16 muestra la flecha en el tiempo de la metodología utilizada.

La anestesia utilizada fue inducida vía inyección intramuscular con Zoletil $(7 \mathrm{mg} / \mathrm{kg})$, propofol $(2.5 \mathrm{mg} / \mathrm{kg})$ y fentanil $(2 \mu \mathrm{g} / \mathrm{kg})$ y se mantuvo con propofol (10mg/kg/hr) vía intravenosa. Los perros fueron intubados después de la inducción y ventilados de forma mecánica durante todo el procedimiento. La concentración de exhalación de CO fue monitoreada por gasometría y ajustada en caso de alteraciones causadas por el procedimiento. Por otro lado, un catéter intravenoso fue colocado en la arteria femoral para la monitorización continua de presión sanguínea y frecuencia cardiaca, otro catéter fue colocado en la vena femoral para el abastecimiento de fluidos. La temperatura corporal fue monitoreada vía termómetro rectal. 


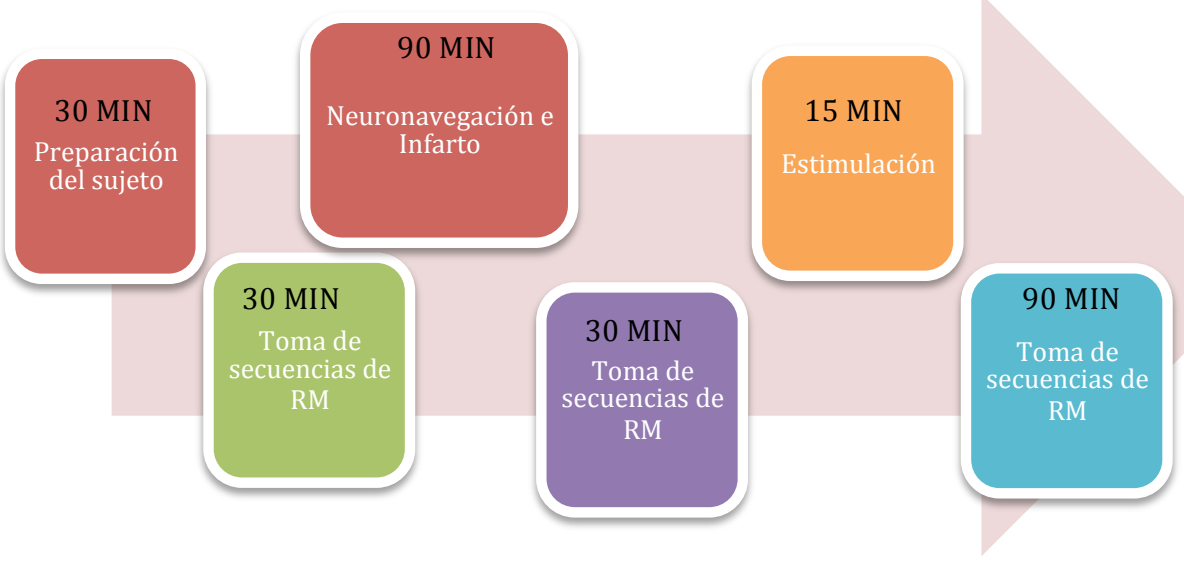

Figura 16. Línea del Tiempo para el protocolo canino

Imagen que muestra la línea tiempo del modelo canino, esta línea de tiempo es hasta 60 minutos post estimulación, sin embargo, fue prolongada hasta 90 minutos en solo algunos sujetos experimentales. Ver anexo I

\subsection{INDUCCIÓN DE EVC ISQUEMICO}

El EVC isquémico fue inducido en un total de 18 animales, por medio de inyección de coágulos autólogos dentro de la arteria carótida interna [( sin distinción de lado) usando un catéter intravascular de 0.035 " vía arteria femoral, bajo angiografía por Rayos X. Los coágulos fueron preparados con $20 \mathrm{ml}$ de sangre autóloga, en jeringas de $1 \mathrm{ml}$ y mantenidas a $4 \mathrm{C}$ por 48 horas antes del procedimiento[25]. La oclusión arterial fue confirmada por medio de fluoroscopia con mapeo y substracción digital, (ver imagen 17). Se uso como contraste sulfato de bario para asegurar el bloqueo de flujo se encontraba en la arteria media cerebral (AMC), la perdida de FSC es confirmado después de la oclusión en la $A M C$, después de una segunda toma de imágenes por fluoroscopia, 30 minutos después de la primera. De los 18 sujetos, se excluye a uno debido a no existir cambios en FSC, y poco bloqueo en AMC. Después de este procedimiento los animales fueron transportados al cuarto de RM para realizar las secuencias de referencia, perfusión y angiografía[27]. 
Ing. Andrea García Quintanar

UAM-Iztapalapa
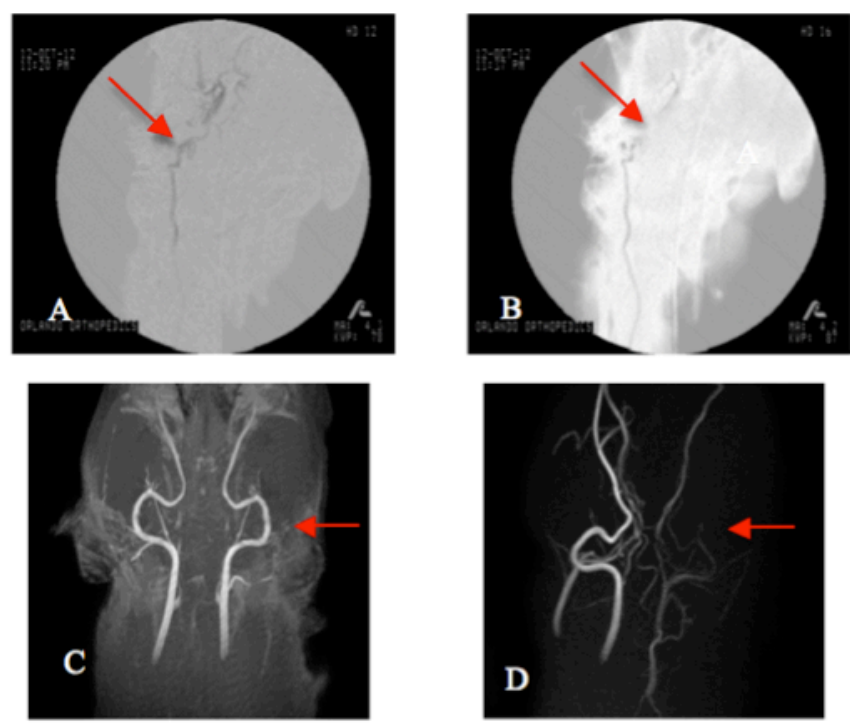

Figura 17. Imágenes de fluoroscopia y resonancia antes y después de EVC

Sustracción digital y Angiografía por Resonancia Magnética, imágenes representativas de un perro antes $(A, C)$ $y$ después de infarto $(B, D)$, correspondientemente. La fecha indica el sitio de oclusión después de la inyección del coagulo autologó.

La posición y colocación del animal resulto importante al momento de realizar las secuencias de resonancia y la estimulación, es por esta razón que se diseño una camilla paramagnética para poder conservar la posición y poder realizar la transportación del animal de un cuarto a otro. Una serie de 6 cápsulas de vitamina en gel fueron colocados con pegamento alrededor de la cabeza para ser usados como marcadores para la neuronavegación. Imágenes de T1W y T2W fueron tomadas como imágenes de referencia para la neuronavegación. Estas imágenes se utilizaron para la localización de los marcadores, del ganglio geniculado y de la raíz del nervio facial [18]. Se posicionó la antena del estimulador encima de la oreja con ayuda de la guía del neuronavegador (Brain Science Tools $(\mathbb{R}$, Holanda), y la antena fue fijada en esa posición con ayuda de un brazo mecánico durante toda la estimulación. En la figura 18 se muestra el equipo utilizado. 


\subsection{NEURONAVEGACIÓN EN EL MODELO}

La neuronavegación fue basada en una serie de 5 marcadores localizados alrededor de la cabeza del sujeto con el fin de ser identificados con imágenes de resonancia T1W. Realizando un registro de las coordenadas espaciales encontradas de los marcadores con las coordenadas del objetivo de estimulación, identificado con las imágenes T2W.
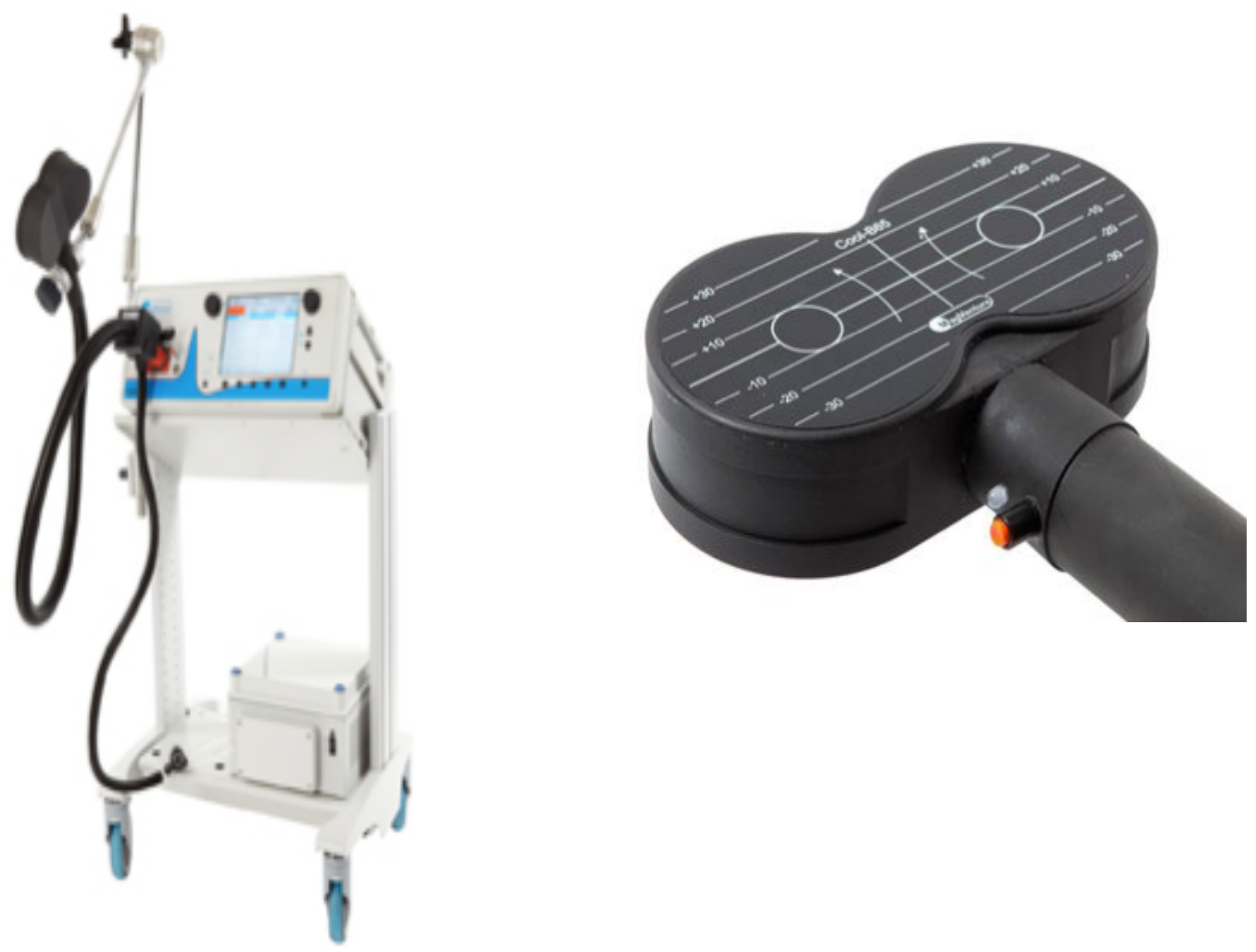

Figura 18. Equipo de Neuronavegación

Izquierda: Imagen del equipo de estimulación utilizado. Derecha: Antena de TMS.

El sistema crea una reconstrucción en 3-D de la cabeza del animal. Un transductor de posición en la antena de estimulación es colocado de tal manera que mediante la reconstrucción es posible posicionar la antena apuntando directamente al centro del objetivo a estimular. La identificación del ganglio geniculado fue mediante la localización de los canales semiculares, ya que se 
Ing. Andrea García Quintanar

UAM-Iztapalapa

encuentra de forma anterior y superior a estos, lateral e inferior a la cóclea y en medio del canal auditivo. El ganglio geniculado fue usado como objetivo, y la línea entre la raíz del nervio facial y el ganglio geniculado fue usado para la alineación del eje de la antena de estimulación[10].

Estos experimentos usaron una antena de estimulación de 174 x 94 x $41 \mathrm{~mm}$ en forma de 8 , con un diámetro interno de $35 \mathrm{~mm}$ y externo de $75 \mathrm{~mm}$ y un devanado de $12 \mathrm{~mm}$ contando con 2 devanados de $2 \times 5$. La estimulación consistió de pulsos bifásicos a $1.5 \mathrm{~T}$ de $280 \mu$ seg de duración con una frecuencia de $10 \mathrm{~Hz}$ a 5 minutos[22]. Dichos parámetros se aplicaron de acuerdo a parámetros antes determinados dado su eficacia en la estimulación del ganglio geniculado [10]. Inmediatamente después de la estimulación, se realizo el traslado al cuarto de RM para la continuación del protocolo .

\subsection{PROTOCOLO IMAGENOLÓGICO}

El protocolo imagenológico consistió en una toma de secuencias a diferentes tiempos; línea de base (LB), Post-Infarto (PI), Post-Estimulación (PEstim), 30 minutos después de la estimulación $(T=30), 60$ minutos después de la estimulación ( $T=60)$ y hasta 90 minutos después de la estimulación ( $T=90)$, solo para algunos sujetos. Las secuencias realizadas se presentan en el anexo II.

Todos los escaners de RM fueron obtenidos usando un equipo Philips $\AA$ Achieva 3T MRI y una antena SENSE $R$ de 8 canales. T1W y T2W del cerebro fueron obtenidos usando la misma geometríca para la facilitación del registro, con 25 rebanadas en coronal y con $230 \mathrm{~mm}$ de Campo de Visión (FOV, por sus siglas en ingles). Las imágenes T2 usaron secuencias Multirebanda de Eco Spin Rápido. Para las imágenes de perfusión se uso la secuencia PRESTO de Philips $\mathbb{R}$ la cual consiste de 40 imágenes dinámicas Contraste de Fase por rebanada, con repetición cada $1.6 \mathrm{~s}$, después de la inyección de agente de contraste (gadolinio: gadopentato dimeglutina $0.5 \mathrm{mmol} / \mathrm{ml}$ ) de $8 \mathrm{cc}$ seguido de $15 \mathrm{cc}$ de solución salina. 

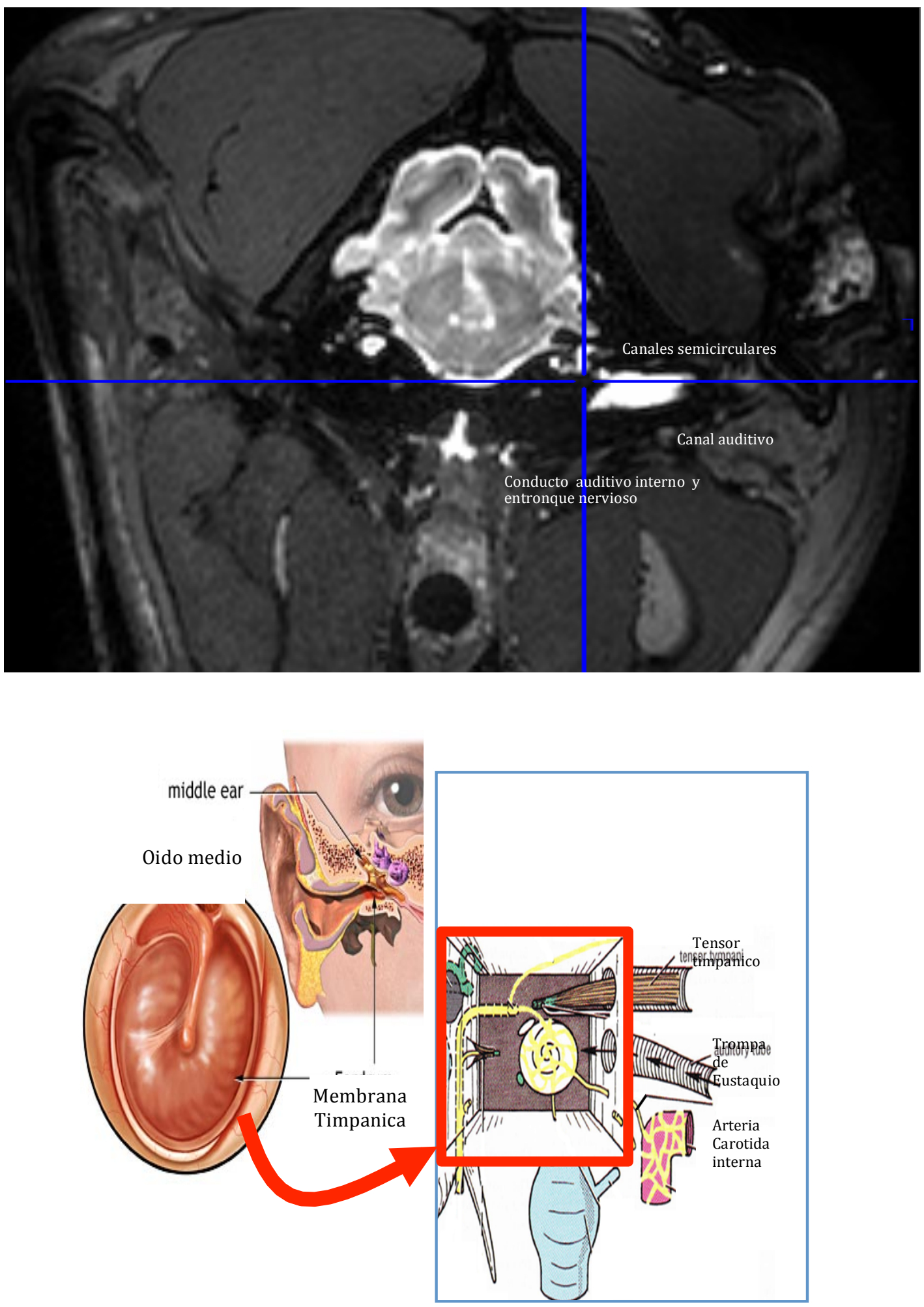

Figura 19. Localización del ganglio geniculado 
Ing. Andrea García Quintanar

UAM-Iztapalapa

En resumen las secuencias fueron generadas con las siguientes especificaciones:

Tabla 2. Tabla de las especificaciones de las secuencias de resonancia magnética utilizadas

\begin{tabular}{|l|l|l|l|l|}
\hline Secuencia & TR/TE ms & FLIP ANGLE $^{\circ}$ & FOV mm & Otros \\
\hline T1_3D_TFE & $7.8 / 3.8$ & 8 & 250 & \\
\hline T2W & $2500 / 384.4$ & 90 & 231.1 & \\
\hline PRESTO & $17 / 25$ & 7 & 230 & \\
\hline MIP 3D_PCA & $15.6 / 4.2$ & 7 & 150 & \\
\hline ASL & $4000 / 20$ & 40 & 230 & 30 Scans Din \\
\hline 2D_QFLOW & $5.6 / 3$ & 10 & 300 & 20 Nr Fases \\
\hline DWI Sense & $2419.2 / 69.8$ & 90 & 230 & 4 Nr Direc. \\
\hline 3D_PCA & $16.2 / 4$ & 7 & 150 & AP/RL/FH \\
\hline P31 Spec & $4500 / .1$ & & & 50/25/50 \\
& & & & NSA 128 \\
\hline
\end{tabular}

Para el análisis de perfusión; los mapas fueron calculados usando el software de Philips PRESTO. De las 25 rebanadas obtenidas 5 mapas fueron calculados para cada una, y se usaron los mapas de INDEX. El análisis se centro en las rebanadas de las 10 a la 14, correspondientes al centro del cerebro y donde el $\mathrm{ACV}$ isquémico estaba localizado.

Para perfusión se realizaron dos tipos de análisis. Un primer análisis fue usando las imágenes de T2W como imágenes de referencia para poder realizar un registro con las imágenes de perfusión. De esta forma es posible crear una máscara del cerebro y poder identificar el segmento de interés en las imágenes de perfusión. El registro fue de tipo manual, escalado-rotado y con la selección de la calidad del registro en preciso. Una vez localizado y segmentado 
únicamente el cerebro, se dibujaron dos regiones de interés (ROI's) cuadradas (20x $20 \mathrm{~mm}$ ), ubicadas en lado izquierdo y derecho de cerebro ( lado isquémico y no isquémico) y posicionadas en la misma referencia anatómica. Posterior a esto se calculo el promedio del índice de perfusión en cada ROI. Para la eliminación de las variaciones de scan a scan se normalizó el lado no isquémico contra el lado isquémico en cada uno de las rebanadas. Después de esto se calculó el promedio de la normalización del índice de perfusión por tiempos, es decir las 5 rebanadas de BL, las 5 rebanadas de PS, etc. Posteriormente se comparó el grupo control contra el grupo de estimulación usando Welch T-Test cada punto de la línea del tiempo.

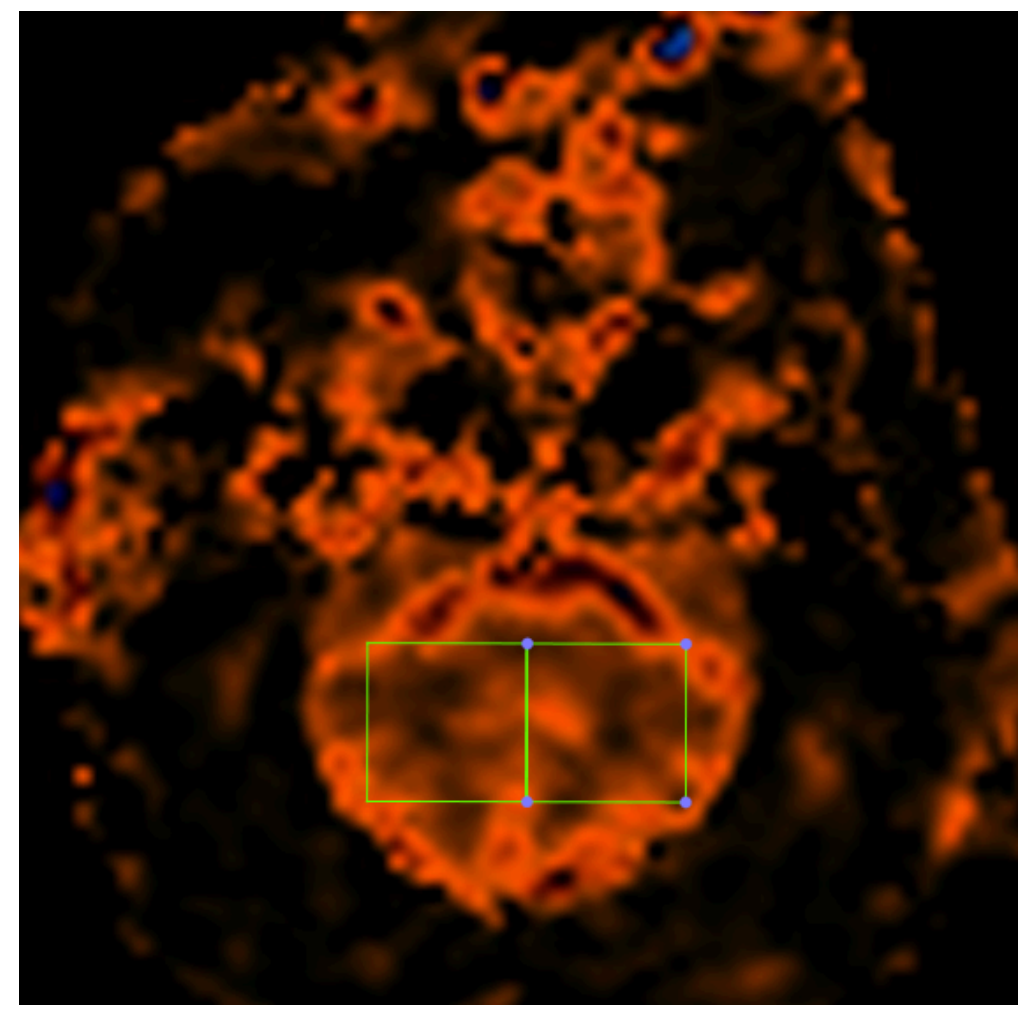

Figura 20. Figura que muestra la colocación de las ROI's en imagen de PRM cerebral.

En esta figura que puede observar que el tamaño de cada ROI es igual a la otra 20x20 mm, adema de estar colocadas una del lado derecho y otra del lado izquierdo. Además de resaltar que tomas las ROI's siempre se localizaron dentro del área de cerebro y nunca fuera de esta área

El segundo análisis consistió en la realización de un registro con imágenes de 
Ing. Andrea García Quintanar

UAM-Iztapalapa

referencia de $\mathrm{T} 2 \mathrm{~W}$, para asegurar que el área era toda la que correspondía al cerebro se realiza una segmentación basada en los contornos usando el algoritmo de Snakes en el software de ImageJ, con 3 iteraciones y un umbral de gradiente de 5. Posterior a esto se establecieron umbrales para lograr la localización de 3 tipos de tejido, umbra (tejido de muy baja perfusión), penumbra (tejido de mediana perfusión) y tejido sano. Esta denominación se propone de acuerdo a la clasificación existente, sin embargo por tratarse de un estudio en agudo no existe una terminología que clasifique el tejido dinámicamente. Los umbrales se seleccionaron del análisis del mínimo y máximo del índice de perfusión encontrados. Para la umbra se eligió el máximo de los mínimos de las rebanadas y se aplico a todos el mismo umbral, la penumbra se eligió como la media del índice de perfusión y el tejido sano fue el índice restante[28, 29]. Lo anterior nos arroja umbrales de 0-15 para umbra, de 16 a 30 para penumbra y de 30 hacia el máximo para el tejido sano. Una vez realizado esta segmentación se contabilizó el numero de pixeles encontrados y se obtuvo un porcentaje de este tejido por rebanada. Posterior a esto se realizo un promedio de acuerdo a los tiempos; 5 rebanadas de LB, 5 de PI, 5 de PEstim, 5 de T30 y 5 de T60. Se realizo la comparación de grupo control contra grupo estimulado.

Por otro lado las secuencias de QFLOW fueron obtenidas bajo la misma posición y se tomaron en LB, PI, PEstim, y cada 10 minutos después de la estimulación[30]. Las imágenes resultantes fueron analizadas con el software de Philips. En cada una de estas se localizaron las carótidas externas derecha e izquierda y se dibujó una elipse ajustada al contorno de la carótida. Esto nos arroja una tabla con las mediciones de flujo y velocidad de cada una de las ventanas de tiempo de la imagen; se tomó la media del flujo y se normalizo contra la media del flujo del lado no estimulado.

Los espectros obtenidos fueron tomados del lado infartado, durante 3 eventos, LB, PEstim y en $T=60$; estos espectros fueron procesados en la consola y bajo el software de Philips. La línea de base fue modulada y se creó un protocolo de 
detección de picos: detección del pico de PCr, tres picos de ATP y el pico de Pi. Se centro el espectro en el pico de PCr y se hicieron las mediciones de ppm y de área bajo la curva de $\mathrm{Pi}$, y picos de ATP. Posteriormente se calculó la relación ATP/ fosfato total, con el fin de obtener el impacto de la estimulación a nivel celular[31]. 
Ing. Andrea García Quintanar

UAM-Iztapalapa

\section{RESULTADOS}

Los resultados se dividirán en 4 secciones principales, los 2 análisis de perfusión, el análisis de Q-FLOW y el análisis de ERM ${ }^{31} \mathrm{P}$.

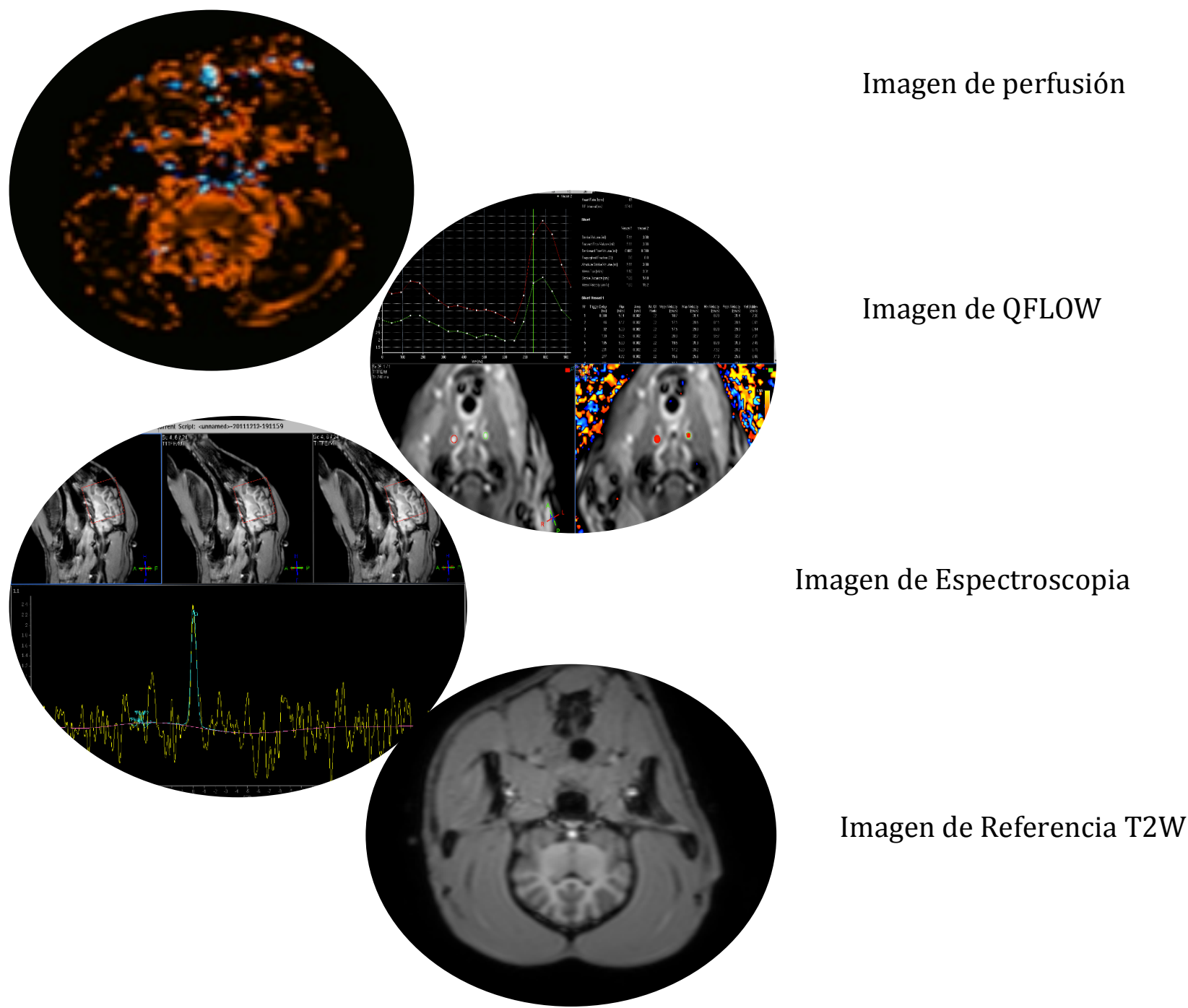

Figura 21. Modalidades de imágenes de RM

Tipo de imágenes e información obtenida en cada tipo de secuencia utlizada. 
En todos los análisis realizados el tejido solo corresponde al cerebro y se usa como normalización en su caso, el lado no infartado. Se tienen 2 grupos, el grupo estimulado de 11 sujetos y el grupo no estimulado de 6, con un total de 17 sujetos mas 1 exclusión.

Antes de llevarse a cabo cada procedimiento se corrieron exámenes de sangre en cada uno de los sujetos para asegurarse de su condición física además de una inspección física por parte del medico veterinario a cargo.

\subsection{RESULTADOS DE PERFUSIÓN}

En la realización del procesamiento de las imágenes de perfusión se noto que existe una diferencia a simple vista entre el grupo control y el grupo estimulado. También se observó la persistencia del aumento de la perfusión debida a la estimulación. Se encontró que la perfusión incrementa del lado de la estimulación desde la cara hasta el cerebro. Sin embargo, se pierde el aumento de la perfusión en la parte externa al cerebro dentro de los primeros 15 minutos. En el cerebro se puede observar que existe una persistencia del aumento de perfusión hasta 60 minutos o mas. En la siguiente figura, se tomó un sujeto representativo de cada uno de los grupos y se muestra la imagen de perfusión en el tiempo. El lado infartado y estimulado esta señalado con la flecha. La notoriedad de la persistencia de la estimulación deja al descubierto la incógnita de los mecanismos exactos utilizados del cerebro para poder mantener una alta perfusión por mas tiempo en el grupo de estimulación cuando comparamos contra el grupo control.

Uno de los primeros análisis realizados se basó en la colocación de 2 ROl's cuadradas con el fin de poder obtener un índice de perfusión que diera pie a la realización de un procesamiento mas robusto. En la siguiente figura se muestra la localización de las ROl's de acuerdo al punto anatómico encontrado. Asi como la gráfica resultante. 
Ing. Andrea García Quintanar

UAM-Iztapalapa

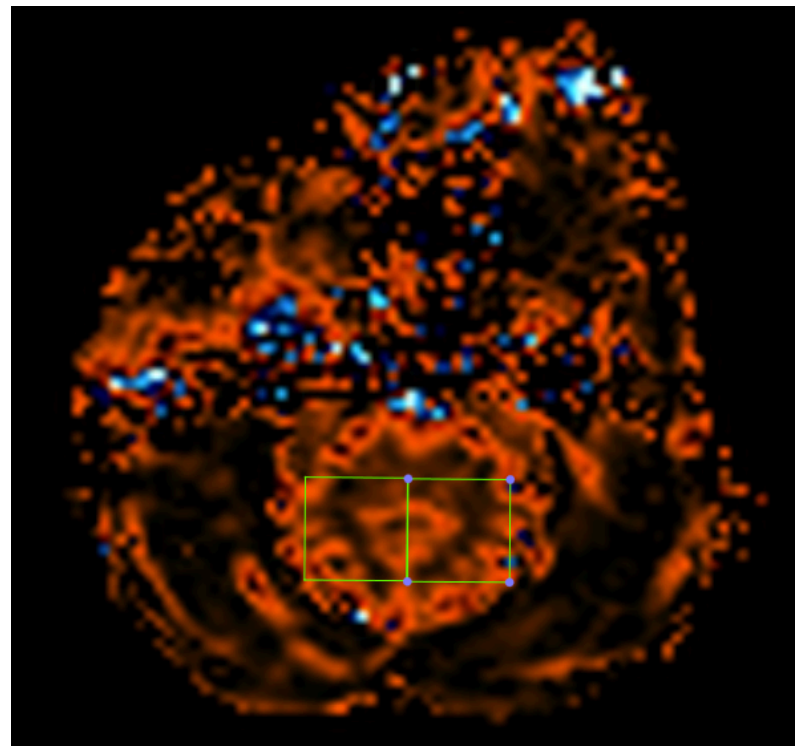

Figura 22. Imagen de perfusión

Imagen de perfusión. Localización de los ROI's cuadrados dentro del cerebro del sujeto. El punto anatómico utilizado fue el punto mas alto de la localización de los ventrículos.

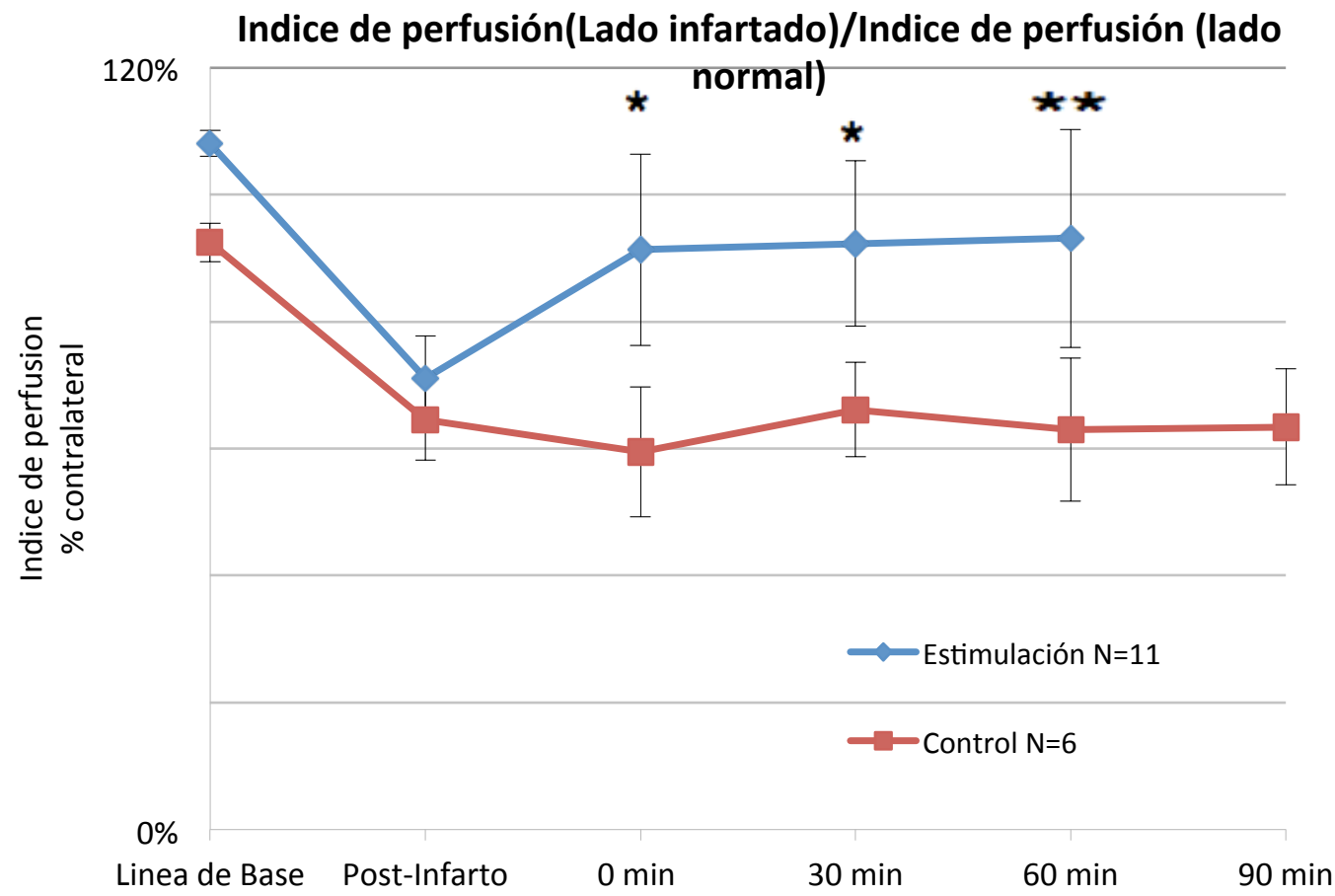

Figura 23. Gráfica del índice de perfusión

Grafica que muestra la media del índice de perfusión del lado del infarto relativo al lado no infartado. EL grupo de estimulación con 11 sujetos y el grupo de control con 6. Las barras de erros son el error estándar de las medias. La flecha azul indica el punto de estimulación. *, $p=0.05,{ }^{* *} p=.10$ 
Al observar los resultados del índice de perfusión con los ROl's, se realizó una segmentación completa del cerebro y se clasifico el tejido en partes; umbra, penumbra y tejido sano. En la figura 24 se muestra la segmentación realizada. El verde es tejido sano, el amarillo es tejido de penumbra y el rojo es tejido en umbra. 

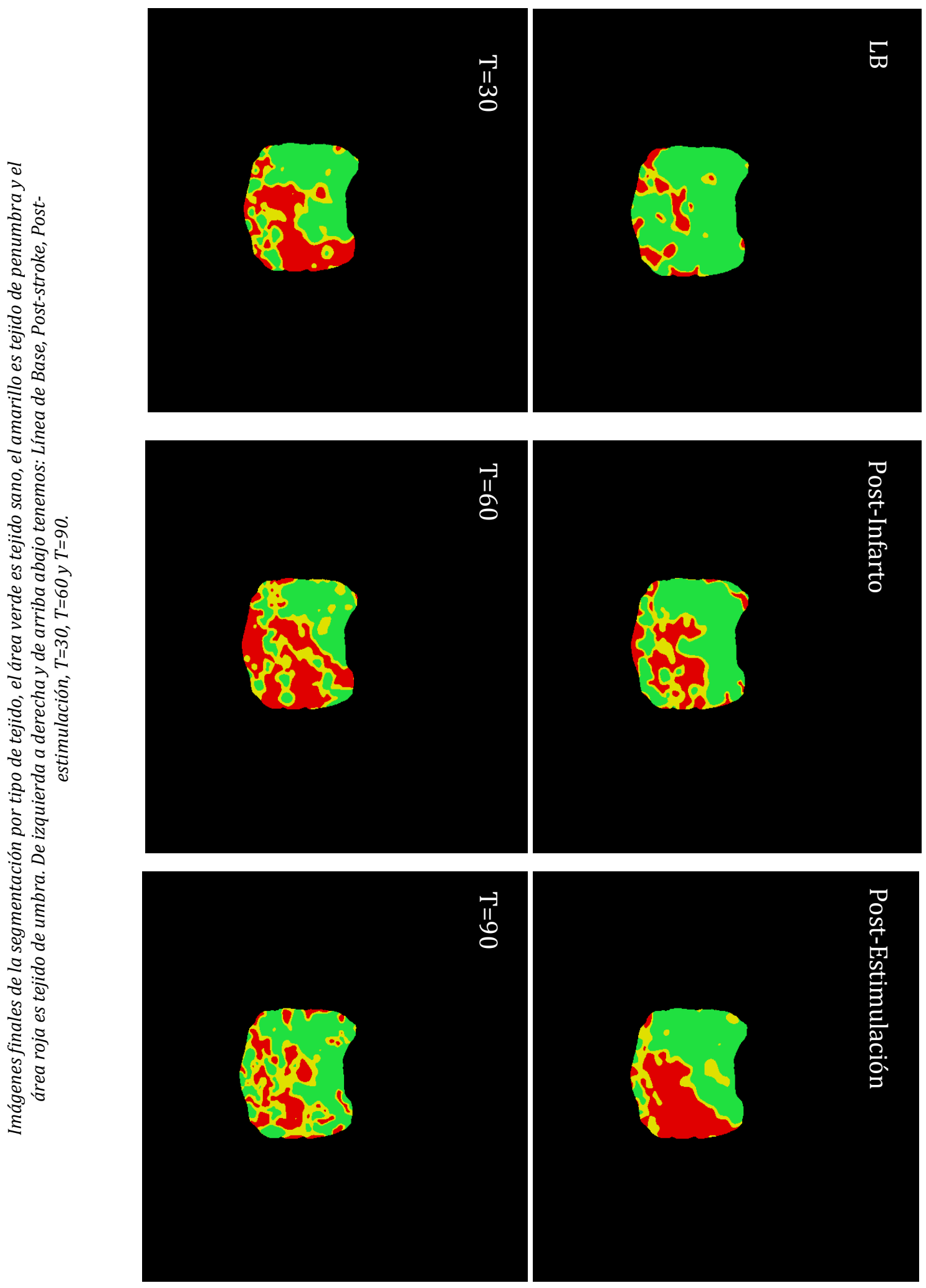
También se muestran las gráficas resultantes de este análisis, del grupo control y del grupo de estimulación.
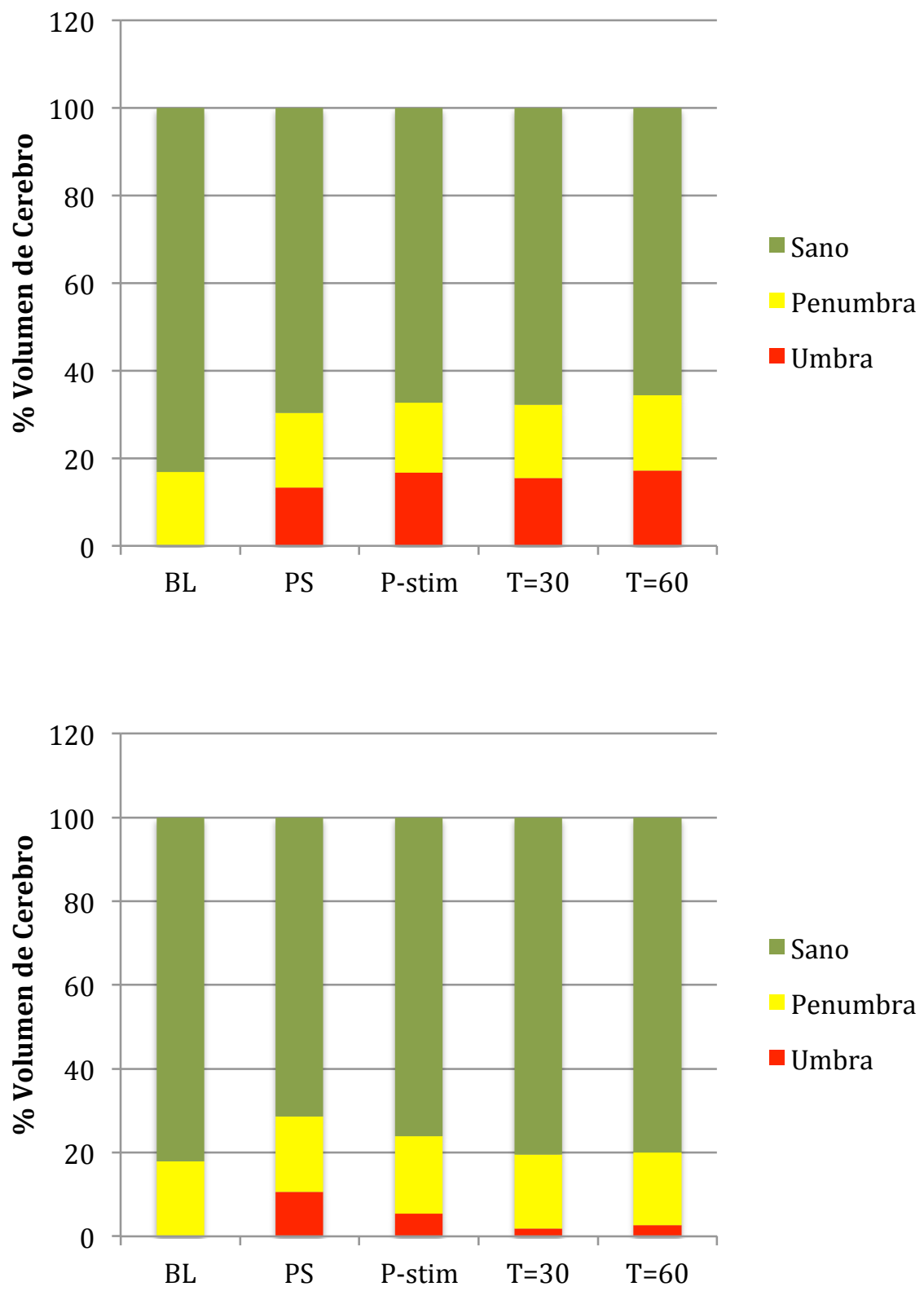

Figura 25. Graficas de \% de Volumen de cerebro por segmentación de regiones.

Grafica superior que muestra el porcentaje de volumen de cerebro en promedio del grupo control, la grafica inferior pertenece porcentaje de cerebro en promedio del grupo de estimulación. El color verde muestra el tejido sano, el color amarillo el tejido en penumbra y el rojo el tejido en umbra, en el grupo de estimulación se nota que en post-stroke tenemos $10.5 \%$ de umbra y a los 60 minutos tenemos el $2.7 \%$. 
Ing. Andrea García Quintanar

UAM-Iztapalapa

\subsection{RESULTADOS DE MEDICIÓN DEL FLUJO}

Las mediciones obtenidas por QFLOW, se realizaron por medio de un ROI de elipse colocado en cada una de carótidas externas, en la siguiente figura se muestra la localización de estas en uno de los sujetos.

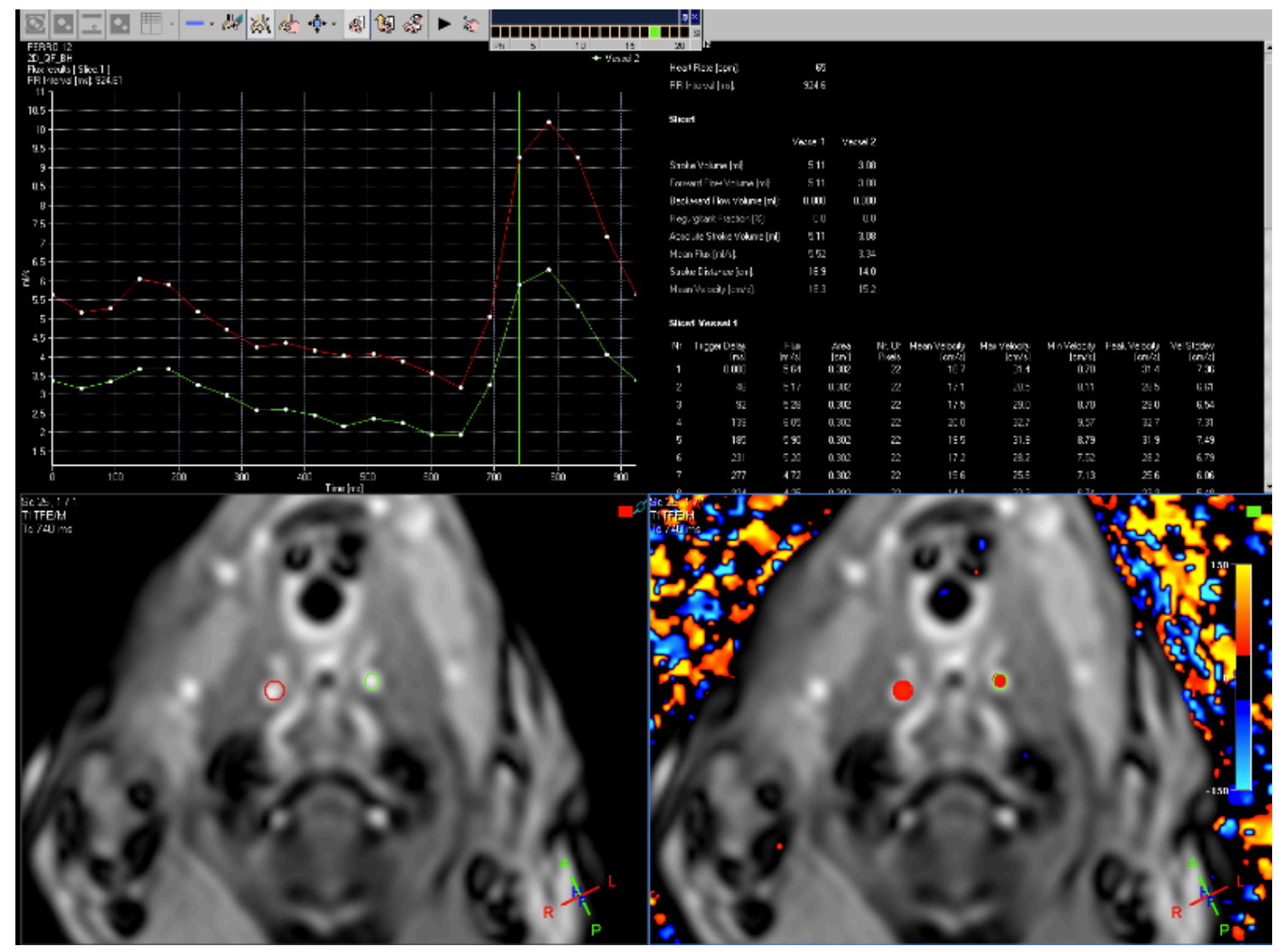

Figura 26. Ventana final del procesamiento del software para Q-Flow

Figura que muestra la forma de la colocación de las ROI's en el software de Philips para el calculo de flujo en las carótidas externas. En la izquierda superior es la grafica del comportamiento del flujo en el tiempo, del lado derecho se muestran las tablas obtenidas por la medición de velocidad y flujo de cada una de las ROI's , asi como el promedio de cada una de estas. En la parte inferior izquierda se muestra la imagen anatómica en la cual se baso para hacer el calculo y en la derecha la visualización de esta imagen en modo PCA/Color. 
Por otro lado la gráfica obtenida de los resultados arrojados de la colocación de las ROI's en las carótidas se muestra en la figura 27 . Se puede observar que es probable la existencia de una compensación propia de los mecanismos acción del flujo sanguíneo, de acuerdo a lo encontrado en la gráfica. Sin embargo el comportamiento del flujo en el grupo de estimulación con respecto al grupo control es un disminución paulatina, es decir con una menor pendiente de punto en punto y con respecto del tiempo. También se observa que con el tiempo ( $t=3)$ estos dos grupos empatan.

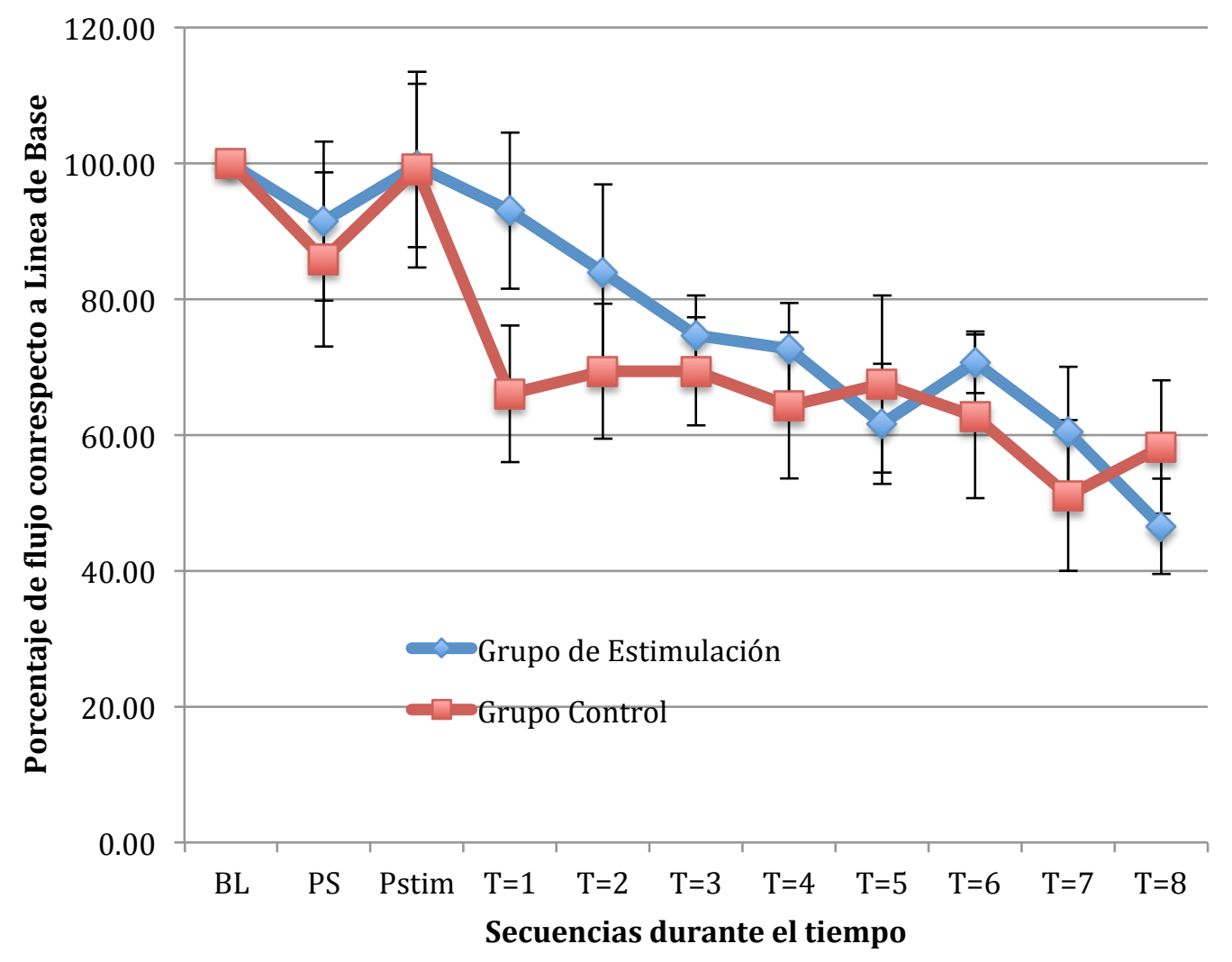

Figura 27. Grafica de Q-Flow

Grafica de los promedios en el tiempo por grupo, la línea azul es el grupo de estimulación y la roja es el grupo control, las líneas de error muestran el error estándar. 
Ing. Andrea García Quintanar

UAM-Iztapalapa

\subsection{RESULTADOS DE ${ }^{31} \mathrm{P}$}

El análisis de los espectros obtenidos de ${ }^{31} \mathrm{P}$ se realizó usando el software de Philips. A continuación se muestra el espectro resultante y los picos detectados.

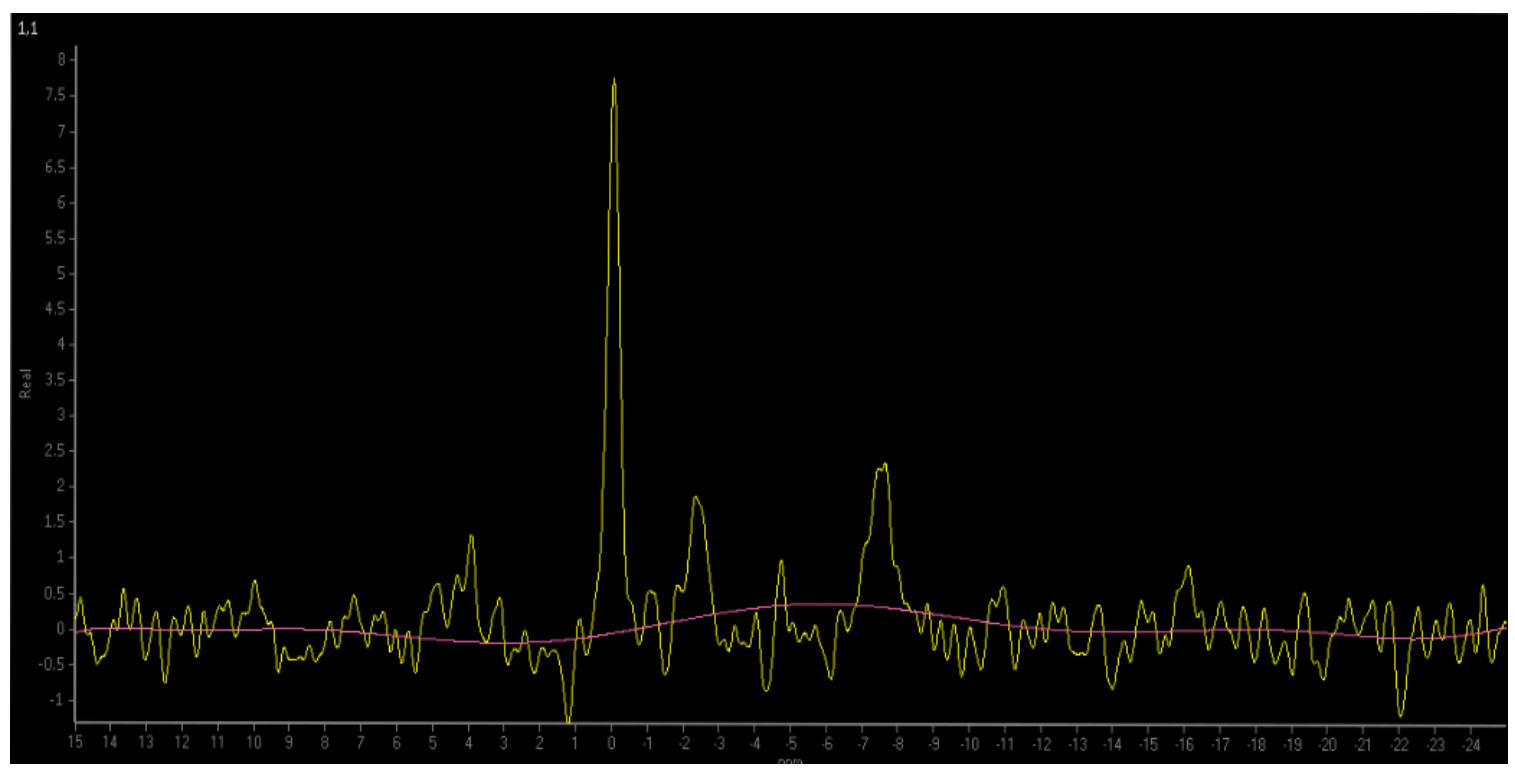

Figura 28. Imagen de ${ }^{31} \mathrm{P}$ ERM

Imagen que muestra uno de los espectros por resonancia magnética obtenidos. Podemos ver que el pico central se refiere al pico de PCr, y a su derecha se encuentran los tres picos de ATP, a su izquierda el pico de Pi. El espectro fue modulado para poder limpiar la línea de base y posterior a esto se corrió un protocolo de detección de picos. El espectro se realizo únicamente del lado infartado. 
Una vez con la detección de los picos se obtuvieron los ppm y área bajo la curva de los tres picos de ATP y de Pi, la grafica de la relación ATP/Fosfato total es la siguiente.

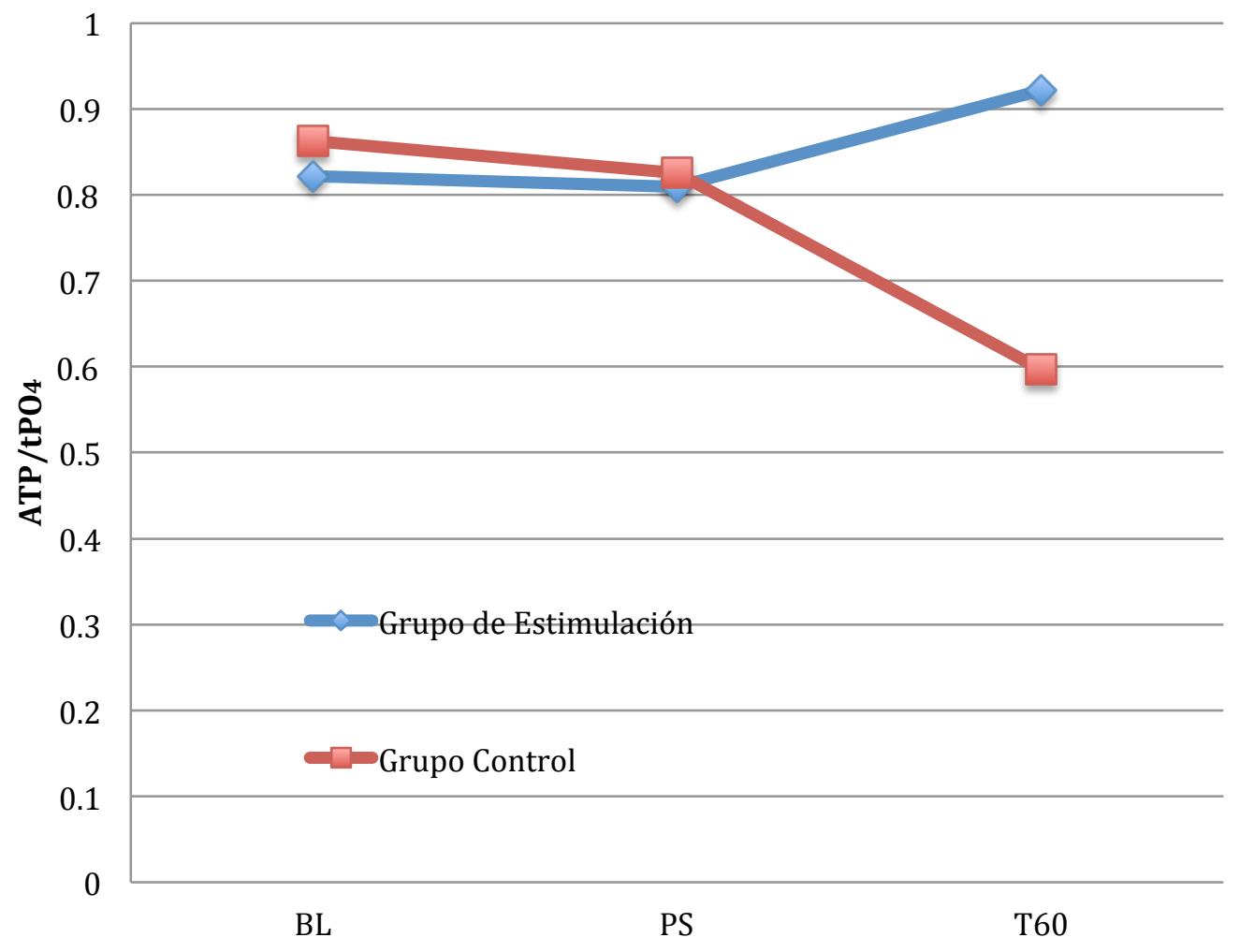

Figura 29. Gráfica de la relación ATP/P total

Grafica de los resultados por grupo del la relación ATP/P total, la línea azul es el grupo de estimulación y la roja es el grupo control. Se puede observar que en el caso del grupo control su relación es del .86 en línea de base y a los sesenta minutos esta cae hasta los .59, en cambio el grupo de estimulación inicia con .82 y a los sesenta minutos se va a.92. 


\section{DISCUSIÓN}

El uso de modelos de EVC isquémico se han caracterizado por la búsqueda de un modelo que no solo brinde similitudes fisiológicas sino que también sea de una fácil reproducción y permita diversos tipos de mediciones. Dentro de los modelos probados están el de oveja, gato y rata. Sin embargo en los últimos años ha surgido la necesidad de la búsqueda de modelos con mayor cercanía a las condiciones clínicas reales en humanos.

El modelo que resulta optimo en la mayoría de las características buscadas es el canino. El modelo resulta ser muy cercano a las condiciones clínicas en el caso de EVC isquémico en humanos. Ha sido usado desde hace pocos años y ha resultado ser altamente compatible con las mediciones por medio de RM.

Por otro lado el uso de coágulos autólogos en lugar de otras técnicas como la oclusión por balón o por medio de agente trombolíticos para provocar la oclusión resulta un modelo mucho mas sencillo. Sin embargo la inyección del coagulo a través de la carótida interna distal y alojado en la AMC, presenta ciertas complicaciones, ya que no siempre se puede tener control sobre el sitio de oclusión. 
Dentro del montaje del modelo y en búsqueda de la aleatoriedad del lado de infarto se causo un sesgo no intencional en nuestros resultados. En un principio la técnica permitía la inserción del coagulo del lado derecho; con la practica de la técnica y el incremento en la habilidad, la mayoría de los sujetos de control obtuvieron inyección del coagulo del lado izquierdo.

Encontramos que la medición de la perfusión en línea de base es 5\% mayor del lado derecho que del lado izquierdo. En general los sujetos del grupo de estimulación tienen el infarto del lado derecho y los sujetos de control del lado izquierdo. Esto se muestra en la figura 23; Sin embargo cuando se realiza la resta de la diferencia en línea de base de los sujetos del lado derecho, se puede observar en la diferencia de las medias del índice de perfusión después de la estimulación sigue siendo estadísticamente significante con una p menor de 0.05 hasta 30 minutos y una $p$ menor de 0.10 para los 60 minutos.

Esta diferencia se espera cada vez menor conforme al paso del tiempo debido a la perdida del incremento de la FSC, se puede presumir que es mayor a los 90 minutos. La estimulación aplicada a los sujetos siempre fue la misma, pero surge la inquietud de saber si los parámetros utilizados son los óptimos en cuestión de persistencia de los efectos de la estimulación.

La medición de la media del índice de perfusión fue a través de la localización de ROI's cuadradas. La localización de estas resultó de un análisis que comprendió la segmentación del cerebro en base a visualización. Se mencionó en los antecedentes que existen ciertas partes del cerebro que no tienen índice de perfusión, como los ventrículos. Así que se dio a la búsqueda de un área donde se pudiera tener la máxima área de cerebro y la mínima variación debido a las estructuras adyacentes. El resultado fue la notoriedad de que el tamaño del cerebro no tiene una gran variación de sujeto a sujeto y que la localización 
Ing. Andrea García Quintanar

UAM-Iztapalapa

debería de contemplar los ventrículos para que estos sirvieran como una referencia anatómica.

Posterior al análisis con ROl's se realizó una segmentación definida por 3 áreas, tejido de: umbral, penumbra y sano. Para la segmentación de estos tejidos se utilizaron imágenes .tiff. Estas imágenes hacen una normalización con respecto al valor máximo de la imagen y nos arrojan imágenes con escala de intensidad de 0 a 255, 16 bits. Después de esto se propusieron los umbrales de 0 a 5, de 6 a 15 y de 16 a 255, se realizó un mismo análisis con su respectiva proporción con imágenes tipo .raw, obteniendo resultados similares.

El resultado de este tipo de segmentación se puede ver en la figura 24 y la grafica de un grupo con respecto a otro en la figura 25. Se puede observar que la segmentación no fue unilateral sino sobre todo el cerebro es por eso que se comprueba la existencia de las estructuras sin perfusión y se restan en línea de base al hacer las gráficas.

También se nota en las gráficas de la figura 25 que el grupo de control con respecto al grupo de estimulación mantiene un porcentaje de área mucho mayor con tejido de umbra. En la gráfica del grupo de estimulación notamos que el porcentaje de tejido de umbra disminuye con respecto al tiempo, suponiendo un $100 \%$ de umbra después del infarto, a los 60 minutos el tejido de umbra existente es de solo un $25.6 \%$, esto representa que se esta salvando hasta el $75 \%$ del tejido infartado y que existe un aumento del tejido reversible de hasta un $11 \%$. En cambio en el grupo control, vemos que se da un incremento en el área de umbra de hasta un $128 \%$. Estos últimos datos nos arrojan información relevante acerca de la proporción de tejido salvado gracias a los efectos de TMS. 
Para este estudio, se usaron imágenes de línea de base por RM y un sistema de neuronavegación para poder enfocar el sitio de estimulación, este proceso se realizo en cada uno de los sujetos. Se observó que la adecuada estimulación del nervio facial era evidente cuando se daban 3 fenómenos: guiño del lado estimulado, dilatación de pupila y movimiento del hombro.

Otro de los análisis realizados fue la medición del flujo en las carótidas externas, los hallazgos se muestran en la figura 27. Para la medición del flujo se utilizo el software proporcionado por Philips $\AA$.

En la figura 27, la gráfica nos muestra la variación del flujo de la carótida del lado estimulado con una normalización a línea de base, podemos observar que en post-estimulación existe un incremento del flujo en ambos grupos por la acción natural de respuesta del sistema nervioso que reacciona con un incremento en el flujo, sin embargo podemos notar que en el grupo de estimulación el flujo se mantiene con un aumento significativamente mayor al grupo control hasta por 30 minutos posteriores a la estimulación.

En los resultados de Espectroscopia por RM, las secuencias fueron tomadas solo del lado infartado. El procesamiento del espectro, el software nos arroja dos señales con las cuales podemos centrar el espectro, la señal real y la modulada, lo que se realizo fue una aproximación de la señal real a la modulada para que este proceso sirviera como limpieza de línea de base y evitar los posibles picos negativos propios del ruido.

Con ayuda del software se aplicaron dos protocolos para la identificación de los picos metabólicos, el primero hace la identificación únicamente de los picos de ATP, Pi y PCr y el segundo desglosa los picos de Pi, dado que el vóxel alojaba diferentes tipos de tejido esto indica que existen al menos 3 picos de $\mathrm{Pi}$. La forma de establecer la localización de estos picos fue por medio del $\mathrm{pH}$ esperado, buscando que el tejido isquémico tuviera $\mathrm{pH}$ mucho mas acido. 
Ing. Andrea García Quintanar

UAM-Iztapalapa

La relación de ATP/fosfato total, para el cálculo de la medición del nivel metabólico celular se realizó a través de la suma de las áreas de ATP y se dividió entre el área de $\mathrm{Pi}$; esta relación nos indica la actividad celular en el momento de la medición. Sustentamos que en muchas ocasiones al existir un aumento de la perfusión no es un índice directo de la homeostasis celular. Sin embargo este índice nos indica directamente la situación actual celular. En la figura 29 podemos observar la gráfica de los dos grupos, en el grupo de estimulación a los 60 minutos post estimulación podemos observar que existe un aumento en la actividad celular debido a la estimulación. Por el contrario en el grupo control se observa una caída de esta actividad con respecto en el tiempo.

La técnica de Espectroscopia por RM, nos permite hacer una cuantificación de la activación del metabolismo para poder medir los cambios celulares que la estimulación provoca. 


\section{CONCLUSIÓN}

Una de las ventajas que se presentaron al realizar este modelo en caninos fue el potencial de realizar mediciones de flujo, perfusión, difusión y de espectroscopia por resonancia magnética en etapas muy agudas en el EVC isquémico.

Sin embargo existen diferentes variables sobre las cuales no se pudo tener un control estricto como lo es la variabilidad en el tamaño del infarto de sujeto a sujeto, debido a la falta de control sobre el sitio de alojamiento del coágulo. Lo anterior resulta en la explicación de la exclusión de uno de los sujetos, ya que este no demostró ningún área de perdida de FSC después de la oclusión en la AMC. Este tipo de respuestas nos muestran lo parecido del modelo a la realidad clínica. Aún y con las variaciones observadas de sitio de oclusión y tamaño del infarto, los efectos de la estimulación magnética del nervio facial muestran una diferencia significativa en los niveles de FSC.

Los resultados encontrados en estos experimentos muestran un incremento significativo y persistente de FSC en casos de infarto isquémico, debidos a los efectos de TMS en el nervio facial. La restauración del FSC con un método no invasivo como lo es la TMS parece ser un efecto con una alta persistencia después de la estimulación del nervio facial. Esto sugiere que este tratamiento puede ser benéfico en la clínica para los protocolos a seguir en los casos de 
Ing. Andrea García Quintanar

UAM-Iztapalapa

infarto cerebral. Sin embargo aun no conocemos la duración total de los efectos de la estimulación con los parámetros utilizados.

El uso de IRM como herramienta en la evaluación de tratamientos para la restauración de FSC en casos de isquemia resulta sumamente útil cuando el modelo es agudo. Además de que tiene la ventaja de poder ser un sistema que nos brinda información casi en tiempo real. Además de que nos brinda la oportunidad de dar seguimiento para la comprensión del comportamiento de los modelos existentes o modelos a proponer.

La espectroscopia por RM, nos arrojo resultados altamente valiosos, que nos hablan de los efectos a nivel celular del tratamiento probado. Cabe resaltar que el vóxel utilizado para esta secuencia contiene al menos los tres tipos de tejidos y que no se mide un área (umbra, penumbra o sano) en específico. La localización, amplitud y área de los picos son altamente susceptibles al tratamiento previo a la aplicación del protocolo de búsqueda de picos.

El protocolo de los tres picos de ATP y Pi, se notó que lo mas adecuado en este caso no era una obtención del pH del tejido, si no el uso de la relación metabólica.

La ERM no ha sido implementada en protocolos clínicos debido a la dificultad de contar con este tipo de antenas, sin embargo resulta útil en la investigación y sirve como sustento del efecto real y existente a nivel celular de la TMS. Se sugiere su posterior uso para la comprobación de los efectos en otros tipos de técnicas de restauración del CBF en modelos de isquemia cerebral.

El uso de la perfusión como indicador principal en el modelo, se contradice con los protocolos clínicos en donde si bien se usa, la secuencia prioritaria es la difusión, lo anterior debido a que con las secuencias de perfusión se puede observar un cambio inmediato debido a los efectos del tratamiento. Se observó 
que el establecer los umbrales en las imágenes tiff era necesario para establecer el área reversible. Estos umbrales se definieron con respecto a artículos revisados.

Aunque no se puede llegar a una discriminación completa del tipo de infarto, se nota que es una técnica que se puede utilizar para realizar la medición de los efectos en cualquier tipo de EVC y que esto nos puede llevar a la comprobación de la posible utilización de TMS en nervio facial sin importar el tipo de infarto.

Una de las observaciones realizadas en el momento de la estimulación es que al existir una pequeña desviación en la posición de la antena, del orden de $1 \mathrm{~cm}$, esto puede ser la causa de la nula o poco persistencia de los efectos de la estimulación del nervio facial.

Para la medición del flujo de las carótidas existe cierta variabilidad con respecto al tamaño de la ROI dibujada, es por esto que se trató de ajustar lo mas cercano al diámetro de la carótida. En la figura 26 se muestra la ventana desplegada por el software para realizar la determinación del tamaño, sin embargo esto no pudo realizarse en todos los sujetos o en todos los tiempos ya que debido a la disminución del flujo y al tamaño anatómico de la carótida el sistema no detectaba como tal un flujo mayor. Sin embargo la ROI se aproximo a la silueta de la carótida en la imagen inferior izquierda.

Los resultados hallados en este trabajo nos permiten desarrollar nuevas herramientas para la evaluación de tratamientos de EVC. También podemos observar que dada la problemática global este trabajo exigió la cooperación entre distintas disciplinas. Por lo anterior que los resultados han podido ser analizados desde diversos puntos de vista. 
Ing. Andrea García Quintanar

UAM-Iztapalapa

El tratamiento agudo de TMS en EVC resulta ser efectivo hasta por lo menos una ventana de 60-90 minutos. Durante este tiempo se observo que se da la salvación / modificación de área de tejido que se ha clasificado como umbra, fenómeno atañido a la restauración del flujo colateral y no directamente del segmento de oclusión, que es como los tratamientos se enfocan. 


\section{RECOMENDACIONES DE TRABAJO A FUTURO}

Una de las características importantes de la medición de los efectos de la TMS en modelos isquémicos es que se demuestra que no solo actúa a nivel objetivos a corto y mediano plazo.

Verificación de la estimulación para ser utilizada en casos de hemorragia, sin efectos colaterales importantes. Paso anterior al desarrollo de la portabilidad de un sistema TMS para tratamiento agudo de EVC.

Medición de especificidad y sensibilidad de los parámetros de estimulación con el fin de lograr el mejor efecto con el menor uso de TMS.

Descubrimiento de los posibles efectos secundarios que conlleva el uso de la TMS en humanos, actualmente se desconoce si la propia estimulación puede causar algún tipo de daño debido a que se aplicara a lo largo del canal auditivo, por lo tanto una vez descartados los efectos o bien cuantificados, la experimentación da paso a modelos clínicos.

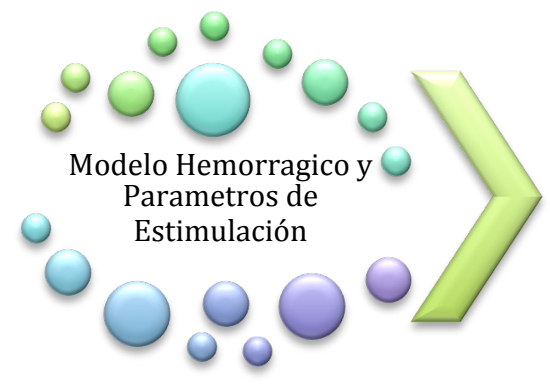

Primer modelo de TMS
Medición de los efectos secundarios
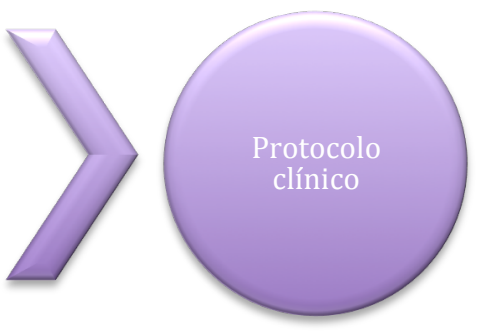

Ajustes y mejoras al hardware
Modelos multicentricos 


\section{LISTA DE FIGURAS Y TABLAS}

\section{TABLAS}

Tabla1. Tabla que muestra el resumen de los hallazgos de realizar TMS en nervio facial. 16

Tabla 2. Tabla de las especificaciones de las secuencias de resonancia magnética utilizadas 48

\section{FIGURAS}

Figura1. Infarto isquémico y hemorrágico 11

Figura 2. Figura que muestra la clasificación por tipo de tejido; umbral y penumbra ___ 12

Figura 3. Principio de la TMS _ 17

Figura 4. Figura que explica la inducción del campo eléctrico en tejido nervioso debido a TMS 18

Figura 5. Figura que muestra el modelo electrónico de los nervios. a) modelo de cable pasivo, b)Modelo

de Hodkin-Huxley. 20

Figura 6. Modelado básico de un sistema de TMS. 20

Figura 7. Ilustración del comportamiento de inducción electromagnética ___ 21

Figura 8 : Figura que muestran la localización anatómica de el nervio facial y sus conexiones así como

la localización del ganglio geniculado.__ 25

Figura 9. Figura que muestra el momento angular del protón.__ 26

Figura 10. Figura que muestra el diagrama general de la generación de señales de la resonancia magnética_ 28

Figura 11. Grafica del comportamiento de T1 y T2_ 30

Figura 12. Grafica de perfusión por RM.__ 32

Figura 13. Localización de los principales metabolitos de ${ }^{31} P$

Figura 14. Localización anatómica de los pares craneales____ 36

Figura 15. Línea de tiempo para el protocolo de ovejas___ 38

Figura 16. Línea del Tiempo para el protocolo canino ___ 43

Figura 17. Imágenes de fluoroscopia y resonancia antes y después de EVC___ 44

Figura 18. Equipo de Neuronavegación___ 45

Figura 19. Localización del ganglio geniculado __ 47

Figura 20. Figura que muestra la colocación de las ROI's en imagen de PRM cerebral.__ 49

Figura 21. Modalidades de imágenes de RM __ 52

Figura 22. Imagen de perfusión___ 54

Figura 23. Gráfica del índice de perfusión___ 54

Figura 24. Segmentación por regiones __ 56

Figura 25. Graficas de \% de Volumen de cerebro por segmentación de regiones. __ 57

Figura 26. Ventana final del procesamiento del software para Q-Flow ___ 58

Figura 27. Grafica de Q-Flow__ 59

Figura 28. Imagen de ${ }^{31} P$ ERM _ 60

Figura 29. Gráfica de la relación ATP/P total___ 61 


\section{BIBLIOGRAFÍA}

1. Roger VL, Go AS, et al. 2012. "Heart Disease and Stroke Statistics-2012 update: A Report from the Heart Association”. Circulation 125:e5-e220.

2. Lloyd---Jones D, Adams RJ, Brown TM, et al. 2010. "Heart disease and stroke statistics - 2010 update: A report from the American Heart Association." Circulation 121: e46-215.

3. CENETEC. 2008."Prevención secundaria, diagnostico, tratamiento y vigilancia de la enfermedad vascular cerebral isquémica, México: Secretaria de Salud."

4. ActivaseTM label, www.activase.com

5. Barber PA, Zhang J, Demchuk AM, Hill MD, Buchan AM. 2001. "Why are stroke patients excluded from tPA therapy? An analysis of patient eligibility." Neurol 56: 1015-20.

6. Cloft HJ, Tomsick TA, Kallmes DF, Goldstein JH, Connors JJ. 2002. "Assessment of the interventional neuroradiology workforce in the United States: A review of the existing data." AJNR 23: 1700-5.

7. Kobayashi M y Pascual A. 2003. "Transcranial magnetic stimulation in neurology." Lancet Neurology2003; 2:145-56

8. Peterchev AV, Rosa MA, Deng ZD, Prudic J, Lisanby SH. 2010. "ECT stimulus parameters: rethinking dosage." J ECT 26: 159---74.

9. Fitzgerald PB, Fountain S, Daskalakis J. 2006. "A comprehensive review of the effects of rTMS on motor cortical excitability and inhibition." Clin Neurophysiol 117: 2584-96. 
Ing. Andrea García Quintanar

UAM-Iztapalapa

10. Borsody MK, Yamada C, Bielawsky D, et al. 2013. "Effect of the pulsed magnetic stimulation of the facial nerve on cerebral blood flow." Brain Research

11. Forbes HS, Schmidt CF, Nason GI. 1939. "Evidence of vasodilator innervations in the parietal cortex of the cat." Am J Physiol 125: 216---19.

12. De graff. 2007. "In vivo NMR spectroscopy: Principles and techniques." Second edition, Willey. Cap 2.

13. Salanga VD, Waltz AG. 1973. "Regional cerebral blood flow during stimulation of seventh cranial nerve." Stroke 4: 213---17.

14. ShahMK,ShinW,ParikhVS,RaginA,MouannesJ,BernsteinRA, WalkerMT,Bh attH,CarrollTJ. 2010. "Quantitative cerebral MR perfusion imaging: preliminary results in stroke." J Magn Res Imag 32: 796---802.

15. Srinivasan A, Goyal M, Azri FA, Lum C. 2006. "State of the art imaging of actute stroke." RadioGraphics 26:S75-S95.

16. TakasawaM,JonesPS,GuadagnoJV,ChristensenS,FryerTD,HardingS, Gillar dJH,WilliamsGB, Aigbirhio FI, Warburton EA, Ostergaard L, Baron JC. 2008. "How reliable is perfusion MR in acute stroke?: validation and determination of the penumbra threshold against quantitative PET." Stroke 39: 870---7.

17. Shaibani A, Khawar S, Shin W, Cashen TA, Schirf B, Rohany M, Kakodkar S, Carroll TJ. 2009. "First results in an MR imaging---compatible canine model of acute stroke." AJNR 27: 1788---1793.

18. Lara R, Maldonado F, Azpiroz J, et al. 2013. "Técnica de neuronavegación para ubicación exacta y precisa de estructuras cerebrales a partir de imagines generadas por resonancia magnética." XXXVI Congreso Nacional de Ingenieria biomedical, CNIB 2013. 
19. Goadsby PJ. 1991. "Characteristics of facial nerve---elicited cerebral vasodilatation determined using laser Doppler flowmetry." Am J Physiol 260: R255---62.

20. Goadsby PJ, Hoskin KL. 1994. "Cerebral blood flow is not coupled to neuronal activity during stimulation of the facial nerve vasodilator system." Brain Res 647: 192---8.

21. D'Alecy LG, Rose CJ. 1977. "Parasympathetic cholinergic control of cerebral blood flow in dogs." Circ Res 41: 324---31.

22. Goadsby PJ. 1989. "Effect of stimulation of facial nerve on regional cerebral blood flow and glucose utilization in cats." Am J Physiol 257: R517---21.

23. Lang J. 1983. Clinical Anatomy of the Head. Springer---Verlag, Berlin.

24. Linder J. 1981. "Effects of facial nerve section and stimulation on cerebral and ocular blood flow in hemorrhagic hypotension." Acta Physiol Scand 112: 1857---93.

25. Khurana D, Kaul S, Bornstein NM for the ImpACT---1 study group. 2009. "Implant for augmentation of cerebral blood flow trial 1: A pilot study evaluating the safety and effectiveness of the Ischaemic Stroke System for treatment of acute ischaemic stroke." Int J Stroke 4: 480---5.

26. Norma Oficial Mexicana, NOM-062-ZOO-1999, Especificaciones técnicas para la producción, cuidado y uso de los animales de laboratorio.

27. Myckatyn TM, Mackinnon SE. 2004. "A review of facial nerve anatomy." Sem Plastic Surg 18: 5--- 11.

28. Mizoi K, Suzuki J, Abiko H, Ogasawara K, Oba M, Yoshimoto T. 1987. "Experimental study on the reversibility of cerebral ischemia. Residual blood flow and duration of ischemia." Acta Neurochir 88: 126---34. 
Ing. Andrea García Quintanar

UAM-Iztapalapa

29. BristowMS, SimonJE,et al. 2005. "MR perfusion and diffusion in acute ischemic stroke: human gray and white matter have different thresholds for infarction." J Cereb Blood Flow Metab 25: 1280-7.

30. HackeW, DonnanG , et al. 2004. "Association of outcome with early stroke treatment: pooled analysis of ATLANTIS, ECASS, and NINDS rt---PA stroke trials." Lancet 363: 768-74.

31. Scott TR, Bennett MR. 1993. "The effect of ions and second messengers on long---term potentiation of chemical transmission in avian ciliary ganglia." Br J Pharmacol 110: 461-9.

32. Dirirnger MN, Edwards D.F et al. 1999. "Predictors of Acute Hospital Cost for Treatment of Ischemic Stroke in an Academic Center." Stroke;30:724728.

33. Mahadevan V. 2012. "Anatomy of the cranial nerves." Elsevier,Surgery 30:3:95-98.

34. Sarrazin J-L, Toulgoat F. et al. 2013. "The lower cranial nerves: IX, X, XI, XII." Diagnostic and Interventional Imaging: article in press.

35. Toulgoat F, Sarrazn J-L, et al. 2013. "Facial Nerve: From anatomy to pathology." Diagnostic and Interventional Imaging: article in press.

36. Guyton C.G y Hall J.E. 2006. "Tratado de fisiología médica." $11^{\text {a }}$ Edición. Elsevier.

37. PHILIPS. 2010."Aplication Guide: Volume 2 Scan Methods." Achieva/Panorama Release 3.2 Series.

38. Verneri $F$, Maggio $P$, et al. 2009. "High frequency repetitive transcranial magnetic stimulation decreases cerebral vasomotor reactivity" Clinical Neurophysiology 120. 188-1194. 
39. Hohmann D, DeMeester C, et al. 1991. "Elektrophysiologische Beurteilung des Nervus facialis bei Patienten mit Akustikusneurinomen" HNO 39:424428.

40. Rimplainen I. Pyykko I, et al. 1993. "The site of Impulse Generation in Transcranial Magnetic Stimulation of the facial nerve" Acta Otolaryngol (Stockh) 113:339-344.

41. Tokimura H, Yamagami M, et al. 1993. "Transcranial Magnetic Stimulation Excites the Root Exit Zone of the facial Nerve" Neurosurgery Vol. 32(3) 414-416.

42. Maccabee $\mathrm{P}$, Amassian V, et al. 1988. "Intracranial stimulation of facial nerve in humans with the magnetic coil" Electroencephalography and clinical Neurophysiology 70:350-354.

43. R.J. Gupta, J.L Benovic, et al. 1978 "The determination of the free magnesium level in the human red blood cell by 31P NMR" J. Biol Chem 253,6172-6176.

44. McRobbie D, Moore E.A, et al. 2007. "MRI, From Proton to picture". Cambridge University Press; 2 edición. 137-166 pp.

45. Bradley J.R y Peter J.B. 1990. "A model of the stimulation of a nerve fiber by electromagnetic Induction". IEEE Transactions on Biomedical Engineering. Vol. 37. No. 6. 588-597.

46. Pascual-Leone A, Tormos-Muñoz J.M. 2008. "Estimulación magnética transcrneal:fundamentos y potencial de la modulacion de redes neuronales específicas". Rev Neurol, 46(Supl 1):S3-S10.

47. Serway y Jewett. 2002. "Physics for Scientist and Engineers". Cengage Learning, 7 edición. Cap 31. 
Ing. Andrea García Quintanar

UAM-Iztapalapa

48. Cohen L.G, Roth B.J, et al. 1990. "Effect of coil design on delivery of focal magnetic stimulation. I. Technical Considerations" Electroenceph. clin. Neurophysiol.

49. Gálvez M, Farias M, et al. 2005. "Calculo de Tiempos T1 y T2 in vitro" Revista Chilena de Radiología.Vol. 11 No. 3109-115 pp. 


\section{ANEXOS}

Anexo I. Pruebas neurológicas utilizadas en la clínica

Cuadro 1. Escala NIHSS de enfermedad vascular cerebral, de los Institutos Nacionales de Salud en Estados Unidos

\begin{tabular}{|c|c|c|}
\hline Grupo & Nombre & Respuesta \\
\hline $1 \mathrm{~A}$ & Conciencia & $\begin{array}{l}0 \text { - alerta } \\
1 \text { - contesta ambas preguntas } \\
2 \text { - estuporoso } \\
3 \text { - corna }\end{array}$ \\
\hline 18 & Preguntas & $\begin{array}{l}\text { O - contesta ambas preguntas } \\
1 \text { - contesta una sola pregunta } \\
2 \text { - no contesta ninguna pregunta }\end{array}$ \\
\hline $1 \mathrm{C}$ & Comandos & $\begin{array}{l}\text { O - realiza ambos comandos } \\
1 \text { - realiza un sólo comando } \\
\text { Z - no realiza ningún comando }\end{array}$ \\
\hline 2 & Mirada & $\begin{array}{l}\text { O - norrnal } \\
1 \text { - parálisis parcial de la mirada } \\
\text { Z - parálisis total de la mirada }\end{array}$ \\
\hline 3 & Campos visuales & $\begin{array}{l}\text { O - no hay pérdida de campos visuales } \\
1 \text { - hemianopsia parcial } \\
\text { Z- hemianopsia total } \\
3 \text { - hemianopsia bilateral }\end{array}$ \\
\hline 4 & Pardlisis facia & $\begin{array}{l}\text { O- sin parálisis facial } \\
1 \text { - parálisis facial menor } \\
\text { 2- parálisis facial parcial } \\
3 \text { - parálisis facial complet }\end{array}$ \\
\hline \multirow[t]{2}{*}{5} & Fuerza de piernas & O- normal \\
\hline & $\begin{array}{l}\text { Izquierdo } \\
\text { Derecho }\end{array}$ & $\begin{array}{l}1 \text { - titubea después de cinco segundos } \\
2 \text { - cae después de cinco segundos } \\
3 \text { - no hay esfuerzo en contra de la gravedad } \\
4 \text { - no hay movimiento } \\
96 \text { - miembro amputado }\end{array}$ \\
\hline \multirow[t]{3}{*}{6} & Fuerza de brazos: & $0-$ normal. \\
\hline & $\begin{array}{l}\text { Izquierdo } \\
\text { Derecho }\end{array}$ & $\begin{array}{l}1 \text { - titubea después de diez segundos } \\
\text { 2 - cae después de diez segundos } \\
3 \text { - no hay esfuerzo en contra de la gravedad } \\
\text { 4- no hay movimiento }\end{array}$ \\
\hline & & 96 miembro amputado \\
\hline 7 & Ataxia & $\begin{array}{l}\text { O - no presenta ataxia } \\
1 \text { - ataxia en un sólo miembro } \\
2 \text { - ataxia en dos miembros } \\
96 \text { miembro amputado }\end{array}$ \\
\hline 8 & Sensibilidad & $\begin{array}{l}\text { O - sin alteración de la sensibilidad } \\
1 \text { - pérdida leve de la sensibilidad } \\
2 \text { pérdida severa o completa de la sensibilidad }\end{array}$ \\
\hline 9 & Lenguaje & $\begin{array}{l}\text { O- sin alteraciones del lenguaje } \\
1 \text { - pérdida leve o moderada de la sensibilidad } \\
\text { 2-afasia leve } \\
3 \text { - mutismo o afasia global }\end{array}$ \\
\hline 10 & Disartria & $\begin{array}{l}0 \text { - sin disartria } \\
1 \text { - disartria leve a moderada } \\
2 \text { disartria severa o anartria } \\
96 \text { intubación }\end{array}$ \\
\hline 11 & Inatención & $\begin{array}{l}0 \text { - sin inatención } \\
1 \text { - inatención leve } \\
2 \text { - inatención severa }\end{array}$ \\
\hline
\end{tabular}


Ing. Andrea García Quintanar

UAM-Iztapalapa

Cuadro 2. ABC Escala de pronóstico para riesgo de evento vascular cerebral en pacientes con isquemia cerebral transitoria

\begin{tabular}{|c|l|l|l|}
\hline A & Edad & 60 años & 1 punto \\
\hline B & Presión sanguinea & $>140 / 90$ & 1 punto \\
\hline C & Falla clínica & Debilidad unilateral & 2 puntos \\
\hline & & Alteración del lenguaje sin debilidad & 1 punto \\
\hline & & Otras situaciones clínicas & 0 puntos \\
\hline D & Duración de sintomas & Sintomas $>60$ minutos & 2 puntos \\
\hline & & Sintomas $10-59$ minutos & 1 punto \\
\hline & & Sintomas $<10$ minutos & 0 puntos \\
\hline
\end{tabular}

Siete días riesgo de evento vascular

$0-4$ puntos: $0.4 \%$

5 puntos: $12.1 \%$

6 puntos: $31.4 \%$

Cuadro 2a. Escala pronbstica $A B C D$ riesgo de pacientes con isquemia cerebral transitoria

\begin{tabular}{|c|c|c|c|}
\hline A & Edad & Más de 60 años & 1 punto \\
\hline \multirow[t]{2}{*}{ B } & Presión sanguínea & >140 mm hg sistólica & 1 punto \\
\hline & & Diastólica > $90 \mathrm{~mm} \mathrm{hg}$ & \\
\hline \multirow[t]{3}{*}{ C } & Falla clínica & Debilidad unilateral & 2 puntos \\
\hline & & Alteración del lenguaje, y sin debilidad & 1 punto \\
\hline & & Otras fallas clínicas & 0 puntos \\
\hline \multirow[t]{3}{*}{ D } & Duración de los síntomas & $\begin{array}{l}\text { Últimos síntomas: } \\
60 \text { minutos }\end{array}$ & 2 puntos \\
\hline & & $\begin{array}{l}\text { Últimos sintomas: } \\
10 \text { - } 59 \text { minutos }\end{array}$ & 1 punto \\
\hline & & $\begin{array}{l}\text { Últimos síntomas: } \\
<10 \text { minutos }\end{array}$ & 0 puntos \\
\hline D2 & Diabetes mellitus & & 1 punto \\
\hline
\end{tabular}

Riesgos de EVC a dos dias.

Menor riesgo ( $0-3$ puntos): $1.0 \%$

Moderado riesgo (4-5 puntos): $4.1 \%$

Alto riesgo (6-7 puntos): $8.1 \%$

Los autores sugieren que los pacientes sean admitidos con isquemia cerebral y tienen un score de 4.00 mayor. 


\section{Cuadro 3. Escala de Glasgow}

\begin{tabular}{|c|c|}
\hline Respuesta ocular & $\begin{array}{l}\text { 1 - sin respuesta } \\
2 \text { - al dolor } \\
3 \text { - a la orden verbal } \\
4 \text { - en forma espontánea } \\
\text { D - se desconoce }\end{array}$ \\
\hline Respuesta verbal & $\begin{array}{l}1 \text { - sin respuesta } \\
2 \text { - incomprensible } \\
3 \text { - inapropiada } \\
4 \text { - desorientada } \\
5 \text { - orientada } \\
\text { D- se desconoce }\end{array}$ \\
\hline Respuesta motora & $\begin{array}{l}\text { 1- sin respuesta } \\
2 \text { - descerebración } \\
\text { 3- decorticación } \\
\text { 4- retiro al dolor } \\
5 \text { localiza al dolor } \\
6 \text { - obedece órdenes } \\
\text { D - se desconoce }\end{array}$ \\
\hline
\end{tabular}

En caso de desconocerse la información por sedación o intubación se da puntaje de uno 
Ing. Andrea García Quintanar

UAM-Iztapalapa

Anexo II. Protocolo en tiempos utilizado.

ISCHEMIC

STROKE

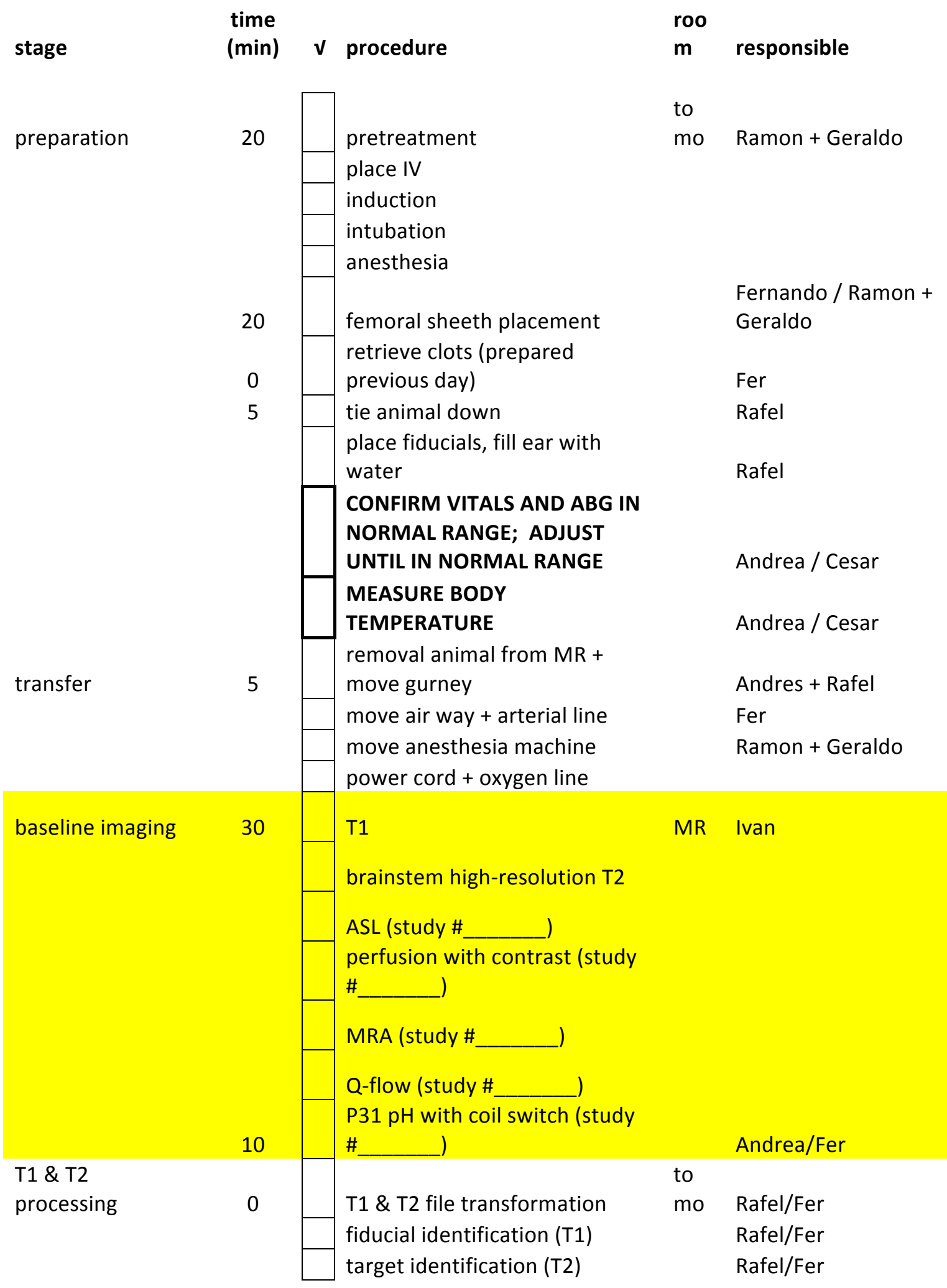




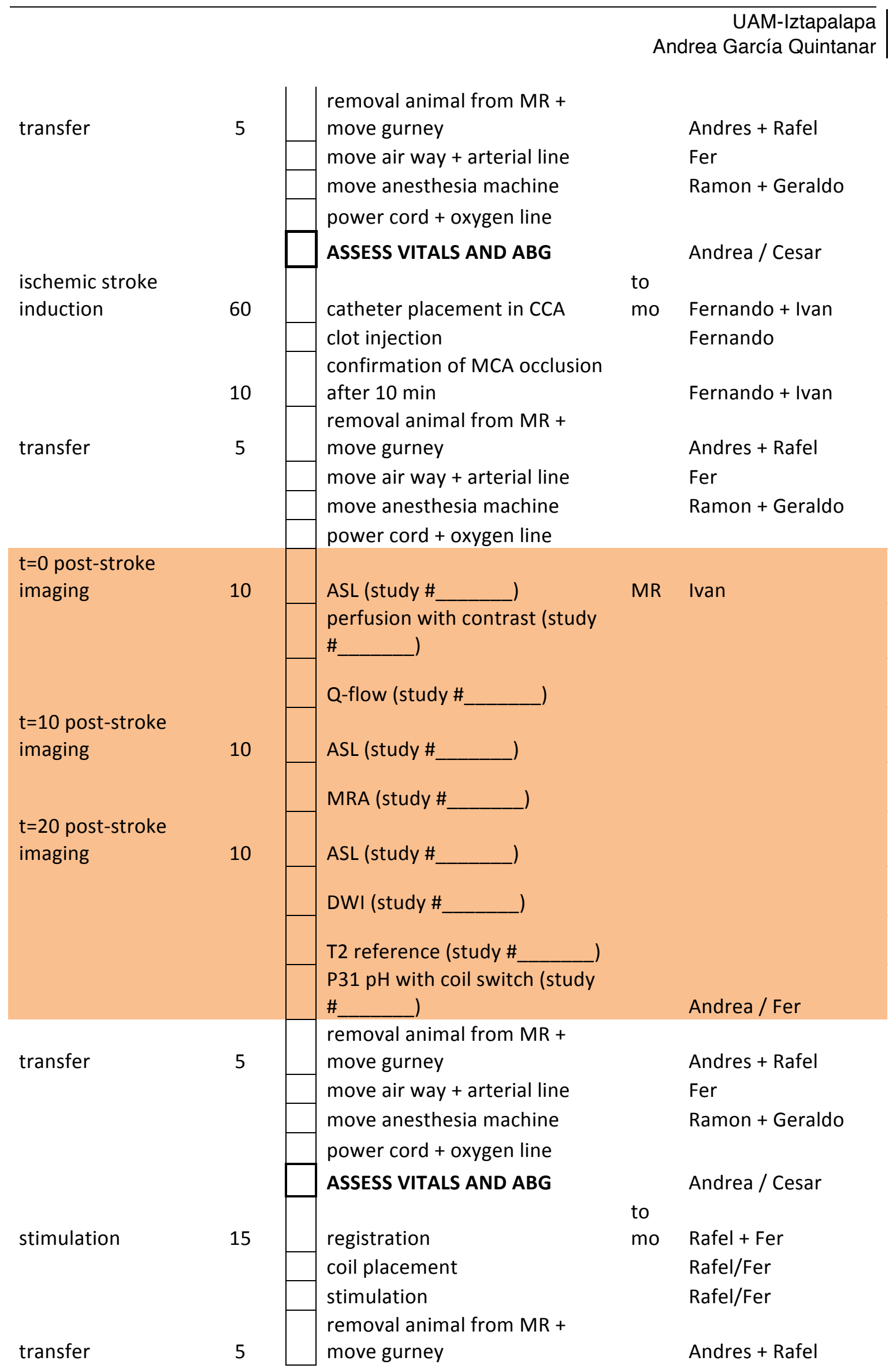


Ing. Andrea García Quintanar

UAM-Iztapalapa

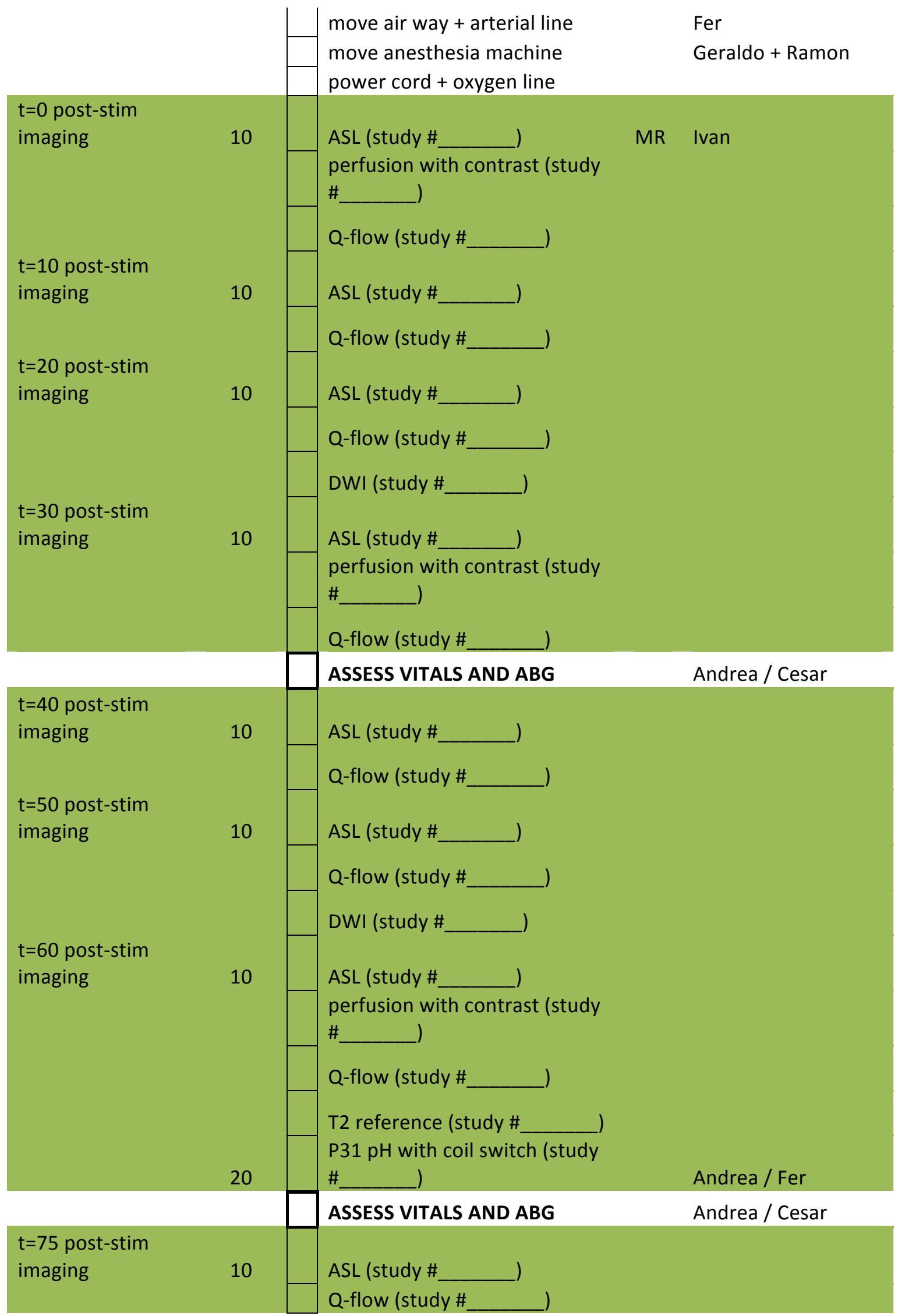




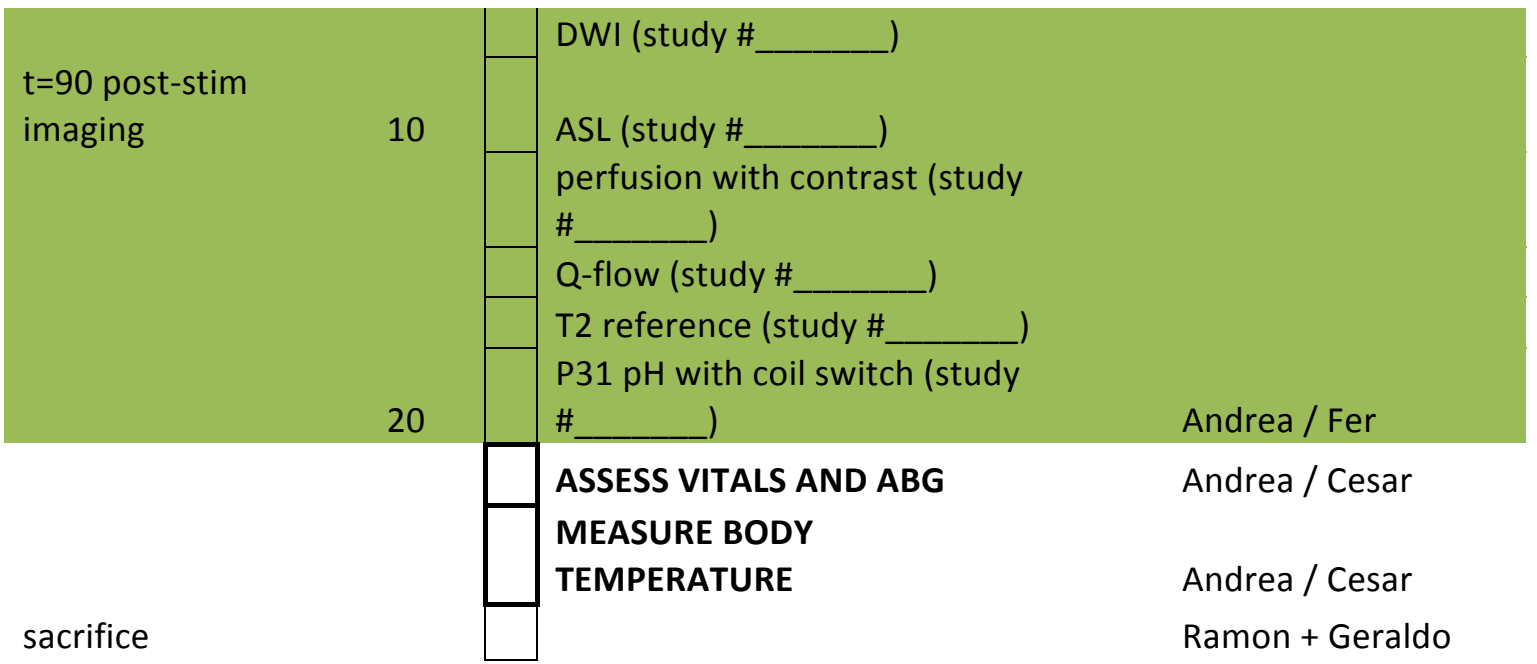

total time $(\min )=355$ 